ملخص: هدفت الدراسة الحالية بصورة أساسية إلى إبراز أهمية مفهوم الدلالة الإكلينيكية والتمييز بينه وبين الدلالة الإحصائية والدلالة

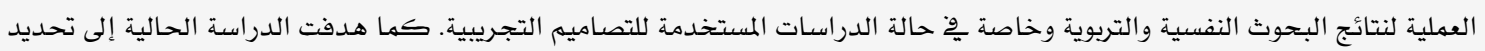

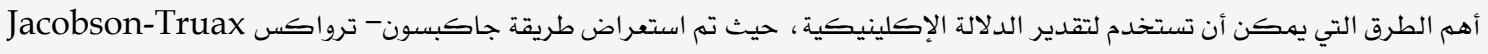

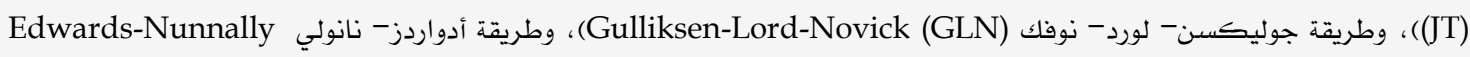

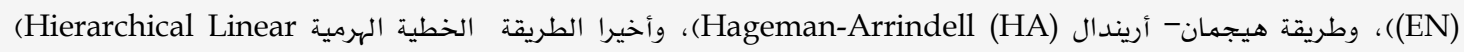

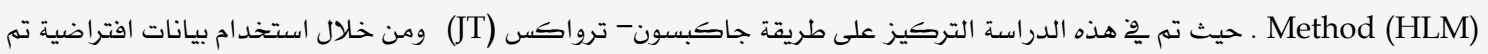
تقديم مثالين: نفسي وتربوي تم من خلالهما توضيح كيفية تطبيق هذه الطريقة. كما حاولت الدراسة الحالية من خلال توظيف طريقة جاكبسون- ترواكس (JT) تقديم نموذج مقترح لفحص الدلالة الإكلينيكية لأثر المعالجة التجريبية على مستوى الفروق بين المجموعات

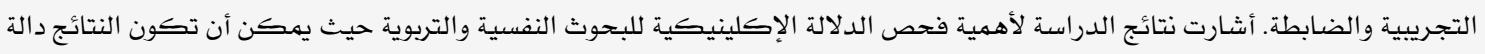

$$
\text { كلمات مفتاحية: الدلالة الإكلينيكية ، الحمليا ولكها غير دالة من الناحية الإكلينيكية سواء على مستوى الأفراد أو على مستوى المجموعات. }
$$

\title{
Clinical Significance of Psychological and Educational Experimental Studies "Analytical Study"
}

Yahya H. Nassar*

United Arab Emirates University, United Arab Emirates

\begin{abstract}
The main aim of this study was to confirm the importance of the concept of clinical significance. Also this study aimed at discriminating among the concepts of statistical, practical and clinical significance. In addition, this study attempted to present the most known methods to estimate the clinical significance of psychological and educational studies. These methods were Jacobson-Truax method (JT), GulliksenLord-Novick method (GLN), Edwards-Nunnally method (EN), Hageman-Arrindell method (HA), and Hierarchical Linear Method (HLM). The current study constraints on the Jacobson-Truax method (JT) and via using hypothetical data, psychological and educational examples were presented to explain how to implement JT method. Moreover, via applying JT method this study attempted to introduce a suggested model to investigate the clinical significance of the treatment on the differences among the groups of the experimental designs. Finally, the results of this study confirmed the value of investigating the clinical significance of the psychological and educational studies because the results could be statistically and practically significant although could not indicate to clinical significance either on the individual or group level.
\end{abstract}

Keywords: Clinical significance, statistical significance, practical significance, Jacobson-Truax method.

*yanassar@yahoo.com 
النفسية والتربوية في الدول العربية، وربيما على الدى

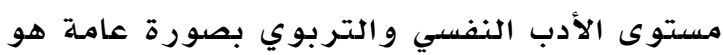
الدلالة الإكلينيكية لنتائج تلك الأبحاث. يشير البحري مفهوم الدلالة الإكلينيكية للنتائج وخاصدة تلك

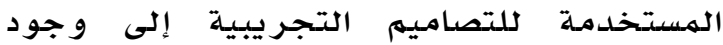
فروق ليس فقط دالة إحصائيا أو/ ودالة عمليا

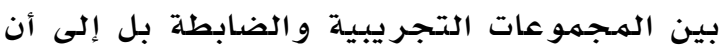

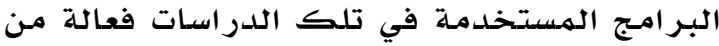

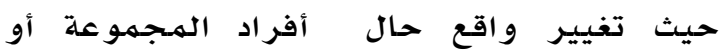
المـجموعات التجريبية من حالة إلى حال أخرى من الهتوقع أن تكون هي الأفضل أو الهرغوب

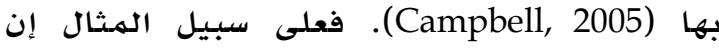
إجراء دراسـة تجريبية تهدف بصورة أساسية إلى

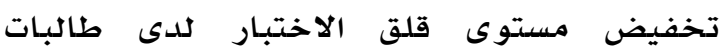

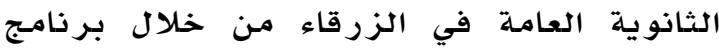

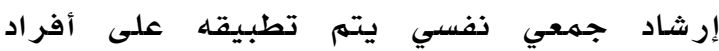

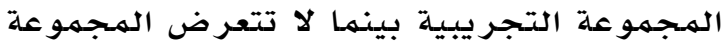

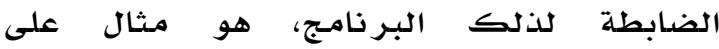

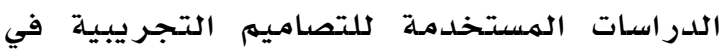
مجال الإرشاد النفسي والتربوي، حيث قد يقوم

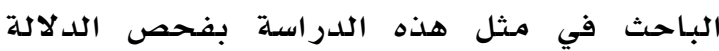

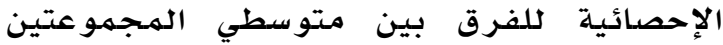

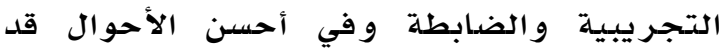

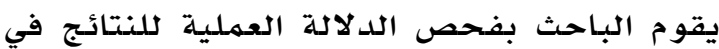

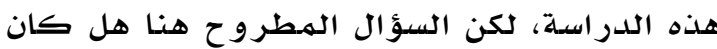

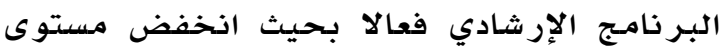

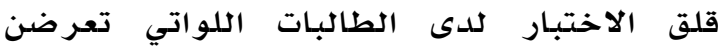
للبر نامج وبحيث تحولوا من طالبات يعانين من قلق الاختبار إلى طالبات عاديات يواجهن

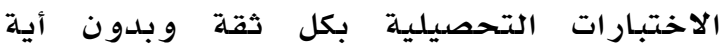
أعراض غير عادية للقلق المعيق لـلأداء. ووفي رأيي أن هذا هو الهدف الأساس للدراسـات القائمـة

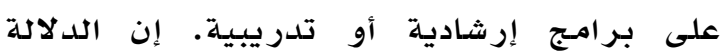
الإكلينيكية للنتائج وفقا للمفهوم المشار إليه تعتبر هامة لفهم وتفسير نتائج الأبحاث النفسية والتربوية، بل أنها قد تعتبر معيارا للحكم على به التقدم أو التحسن أو التراجـع الذي حصل لأفراد

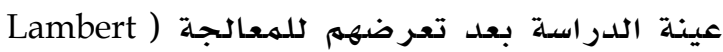
(et al., 2001 الإكلينيكية تبرز من خلال اهتمامها بالتغيير اهرير
يهتم الباحثون في مجال الدراسات النفسية

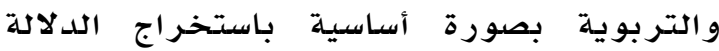
الإحصائية لنتائج أبحاثهم، حيث أن هناك فكرة سائدة بين الباحثين في مـجال الدراسـات النفسية و التربوية أن النتائج الجيدة هي النتائج التي تحقق الدلالة الإحصدائية و على العكس من ذلك فإن النتائج تعتبر ليست ذات قيمة إذا كانت غير إدها دالة إحصائيا. إن مفهوم الدلالة الإحصائية يشير

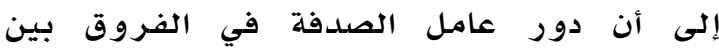
متوسطات المجموعات التجريبية والضـابطة أقل

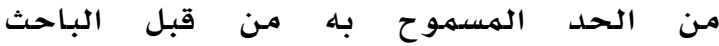

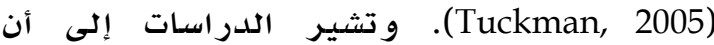
مفهوم أو إستراتيجية الدلالة الإحصائية قد قلد تكون مضلللة في كثير من الاحيان، حيث يمكن أن تكون النتائج دالة إحصائيا نتيجة لتكبير أو تضخيم حجم العينة، بل إنه يمكن تحويل البيانات غير الدالة إحصائيا الى دالة إحصائيا عن

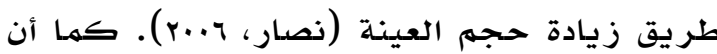
نتائج بعض الدراسات قد تكون دالة مـن الناحية الإحصائية لكنها غير دالة من الناحية العملية

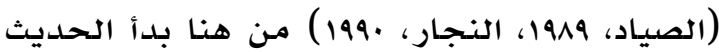
عن مفهوم آخر في الأبحاث النفسية والتربوية

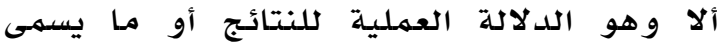
بحجم الأثر (Effect size) (عودة والخول الخليلي، . (1911

ويشير مفهوم حجم الأثر بصورة أساسية إلى أن النتائج الدالة إحصائيا ليس بالضرورة دالة من الناحية العملية، حيث يتم فحص الدلالة العملية لنتائج الأبحاث النفسية والتربوية من

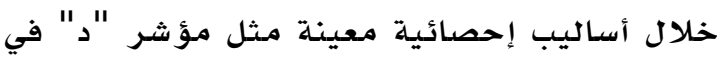
حالة التعامل مـع عينتين مستقلتين أو اختبار

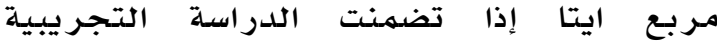
متوسطين أو أكثر، أي أن هناك أسلوبا إحصائيا أو أكثر يمكن استخدامها لفحص الدلالة العملية للنتائج في البحوث النفسية والتربوبة التهية بحيث تكون مكملة لتلك النتائج التي يتم الحصول عليها من الاختبارات الإحصائية التي

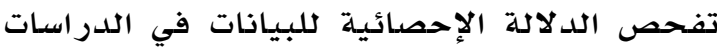

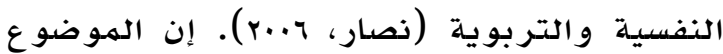

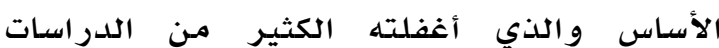




\section{أهمية الدراسة}

إن اعتبار الهدف الأساس من أي تحليل إحصائي هو اكتشاف فيما اذا كان هنالك دلاله إحصائيه

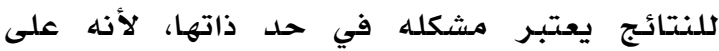
الرغم من أهمية الحصول على نتائج دالة Thompson, ) إحصائيا، فإنها قد لاتكون كافيكانهية 2006) وكما أشار بعض الباحثين فإن مفاهيم

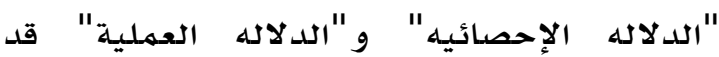

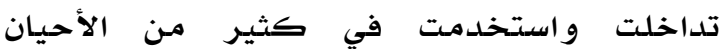
(Hubbar and Ryan, 2000; بطريقه غير صحيحئة (Huberty , 2002). و في هذا السياق، تشير دراسة زئة

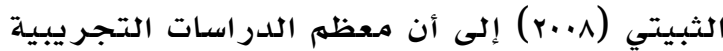
تركز على مستوى الدلالة لاتخاذ قرار حول قبول الفرضية الصفرية أو رفضها دون الاهتمام

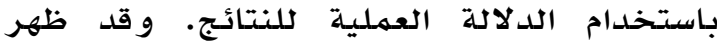

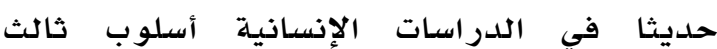
لتفسير نتائج الأبحاث وهو يعتمد بصدوره

أساسيه على ما يسهى بالدلالة الإكلينيكية

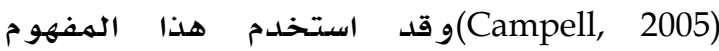
لفحص فيما اذا كانت النتائج التي يته الحصول عليها في الدراسـات التجريبية تعتبر هامـة فعلا

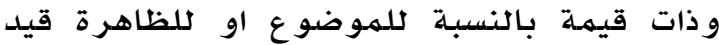
اللدراسة وبصورة اسـاسية تتركز أهمية الدراسلة الحالية بأنها تحاول التمييز بين ثلاثة أنواع من الدلالات التي قد تستخدم في الدراسات النفسية و التربوية وخاصة في سياق التصاميهم التجريبية وهذه الدلالات هي: الدلاكة الاحصدائية

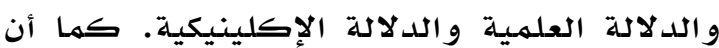
الدراسلة الحالية تسعى لتقديم أساليب إحصائية

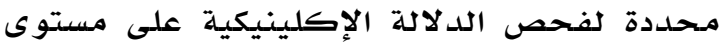

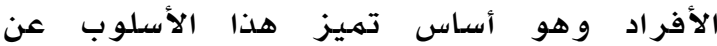
الدلالات الأخرى، كما حاولت الدراسلة الحالية الدالية تقديم أو اقتراح نموذج أو أسلوب يتهم مـن خلادله استخدام الدلاكلة الإحصائية لفحص الألة الدلالة

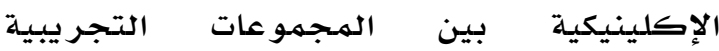

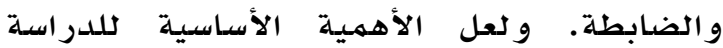
الحالية تكمن في تقديمها طريقة مهمهة للباحثين

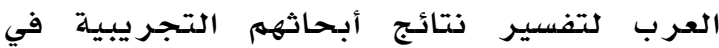
مجال الدراسـات الإنسانية وبالتحديد في مـال

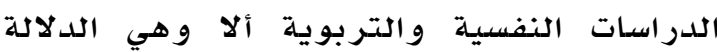

الذي حصل على مستوى كل فرد مـن أفراد الدراسلة على حدة وبالتالي تحلديد مدىى استفادة كل فرد من هؤلاء الأفراد من الهعالجة

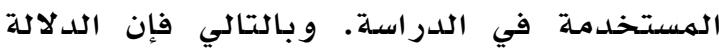
الإكلينيكية تهتم باستكشاف أو اختبار الفائدة التي يمكن تحقيقها من خلال الهعالجات المستخدمة في الدراسـات التجريبية بطرق أكثر فائدة من الناحية العملية مـن الطرق التقليدية

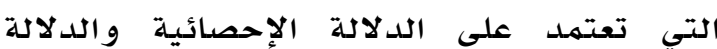

العملية (Hansen, Lambert, \& Forman, 2002).

مشكلة الدراسة

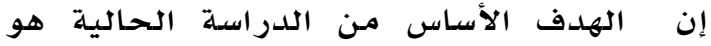

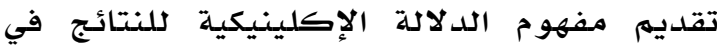

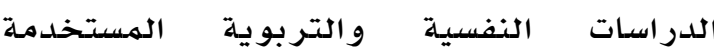
للتصاميم التجر يبية والتمييز بينه وبين مفاهيم

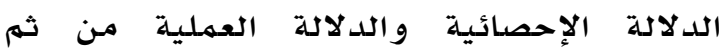
استعر اض لأهم الأسـاليب الهستخدمة في تقدير أو حساب الدلالة الإكلينيكية لنتائج الأبحاث التجر يبية.

أسئلة الدراسـة: حاولت الدراسـة الحالية الإجابة

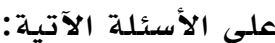

1. ما هو مفهوم الدلالة الإكلينيكية لنتائج

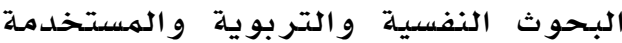

للتصاميم التجر يبية

r. ما هو الفرق بين الدلالة الإحصائية و الدلالة الإكلينيكية

r. هل الدلالة الإكلينيكية هي نفسها الدلادة

العملية للنتائج أم أن هناك فرق بينهماء ع. ما هي الأساليب أو الإجر اءات والتي يمكن

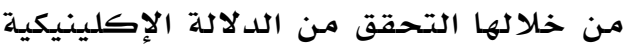
لنتائج البحوث النفسية و المستخدمة للتصاميم التجر يبية؟ ๑. هل يمكن استخدام الدلالة الإحصائية

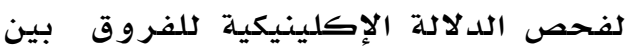

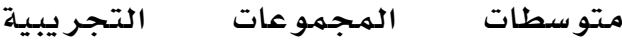
و الضابطة؟ 
الدراسة التحليلية: هي دراسة تقوم على تحليل ظاهرة نفسية أو اجتماعية أو طبيعية، أو مفهوم علمي سواء مـن حيث تعريفه وتوضيح علاقتته بالهفاهيهم المرتبطة به بطرق مختلفة والتي

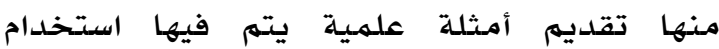
و تحليل بيانات افتر اضية وهذه هي الطريقة التي استخدمت في الدراسة الحالية.

\section{الطريقة و الإجر اءات}

لتحقيق أهداف الدراسـة الحالية و للإجابة على أسئلتها البحثية فإنه تم استخدام الهنهج الوصفي التحليلي حيث تم استعر اض أو توضيح مفهوم

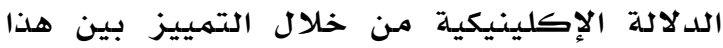
المفهوم من جهة ومفهومي الدلالة الإحصائية

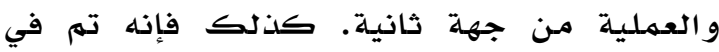
الدراسة الحالية محاولة تقديم بعض الأساليب الإحصائية الأكثر استخداما في الأدب النفسي

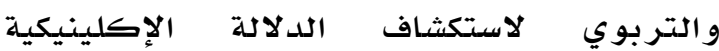

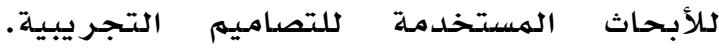
كذلك سيتم في هذه الدراسلة تقديم أمثلة بحثية نفسية وتربوية افتر اضية بغرض توضيح

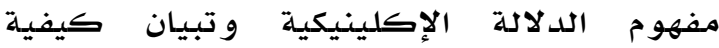
تقدير ها أو حسابها وتفسيرها خاصدة للباحثين الهمتمين باستخدام طرق غير تقليدية لتفسير

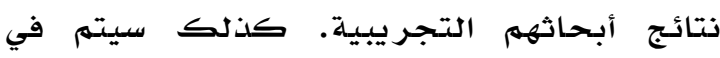

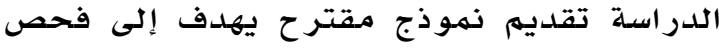

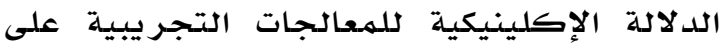

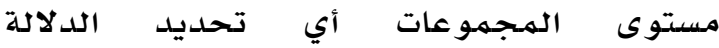
الإكلينيكية لتلك المعالجات على المـجموعات التجريبية و الضـابطة ، حيث يعتمد هذا النموذج

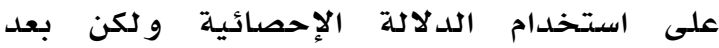
تصنيف أفراد المهجموعتين التجريبية والضـابطة و فقا للمعايير المستخدمة في واحدة من أشهر الطرق المستخدمة في تقدير الإكلينيكية وهي طريقة جاكبسون- ترواكس (Jacobson \& Truax, 1991)

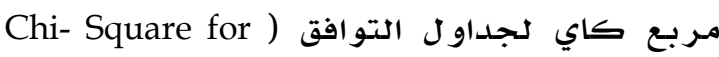
(tabulation cross علاقة دالة إحصائيا بين متغيري الهمجموعة الهمان (تجر يبية - ضابطة) و تصنيف أفر اد العينة تبعا للطريقة المدكورة، وسيتم م تقديم مثال
الإكلينيكية. ومس الجدير ذكره في هذا السياق

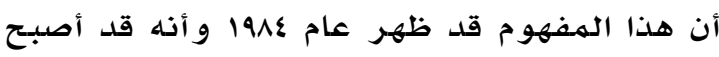
من العناصر الأسـاسية التي تتوقع بعض المـجلات

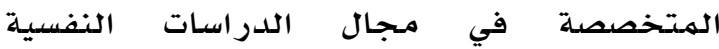
و التربوية أخذها بعين الإعتبار في تفسير نتائج

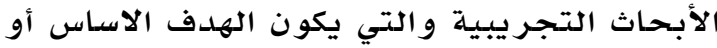

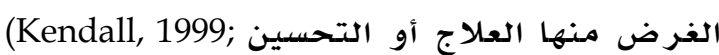
Kendall, Marrs-Garcia, Nath, \& Sheldrik, 1999)

تعريف مفاهيم الدراسة

الدلاكة الإكلينيكية (Clinical Significance):

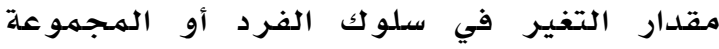

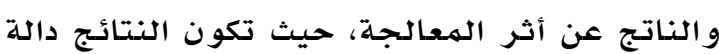

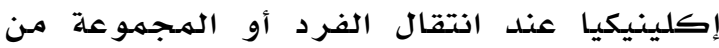

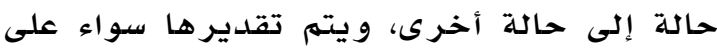
مستوى الفرد أو المهجموعة من خلادل أساليب

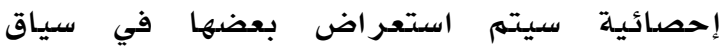

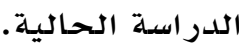

الدلالة الإحصائية (Statistical Significance): أسلوب إحصائي يستخدم لفحص دور أو مقدار احتمال عامل الصدفة في العلاقة بين المتغيرات أو في الفروق بين المتتوسطات، حيث تكون النتائج دالة إحصائيا إذا كان الاحتمال الهال الفعلي ألهاي

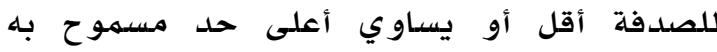

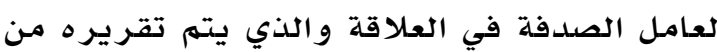
قبل الباحث و المتضمن في الفرضيات الصفرية و البديلة أو يسهى بمستوى الدلادلة الهتوقع.

الدلاكة العملية المتوقعة Expected Practical Significance)

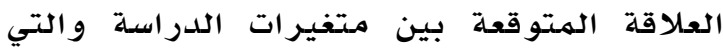
يمكن تقدير ها من خلال مر اجعة الأدب السابق.

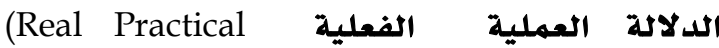
significance)

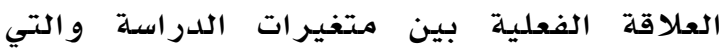
يمكن تقديرها من خلال عملية تحليل بيانات

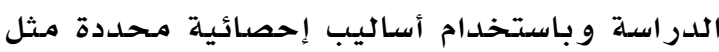

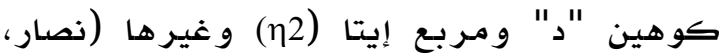
. (r... 


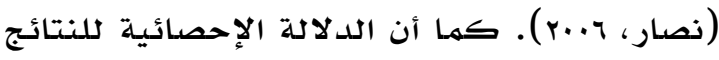

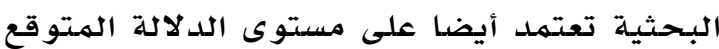

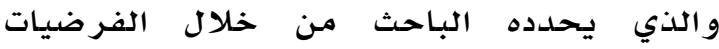
الإحصائية لبحثه، وهنا يجب الانتباه حيث يمكن أن يغير بعض الباحثين قيمهة مستوى الدلالة

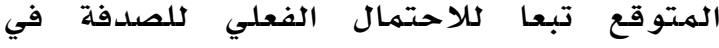
نتائجهم Sig or P و بحيث يتم الحصول في النهاية على نتائج دالة إحصائيا. و من هنا فإنه يمكن القول بأن الاعتهماد على الدلالة الإحصدائية لوحدها في عملية تفسير النتائج البحثية غير البر الهول كافي أو حتى أنه قد يكون في بعض الأحيان مضللا.

الدلالة العملية (Practical Significance) يشير مفهوم الدلالة العملية للنتائج إلى استكشاف قوة العلاقة بين المتغيرات قيد الدر اسلة من خلال استخدام أساليب إحصائية أقل تأثرا بحجم العينة مـن تلك الأساليب الإحصائية التي تعتمد على فحص الدلالة الإحصائية للفروق بين الاحني الهن

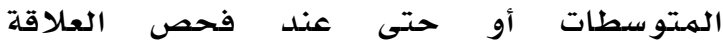
الإرتباطية بين المتغيرات. وبصورة أساسية فإنه يمكن الحصول على نتائج دالة إحصائيا -على وهئى سبيل المثال- مـع عدم وجود فروق كبيرة بين الهتوسطات فقط لأن الباحث قد استخدم عينات كبيرة الحجم نسبيا، حيث أنه من الناحية Standard ) الإحصائية فإن قيمة الخطأ المعياريكئ (Error تزداد قوة الاختبار الإحصائي المستخدم لفحص

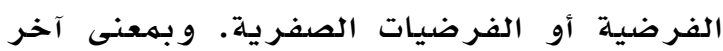

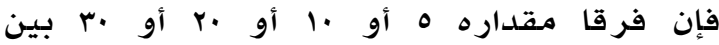

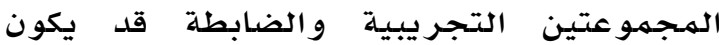
كافيا للحصول على نتائج دالة إحصائيا بالرغم فئه أن الدلالة العملية لتلك الفروق ليس بالضرورة

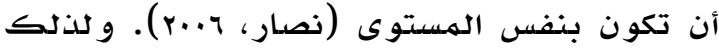
فإن هناك الكثير مـن الهؤسسات الهسؤولة عن الهن

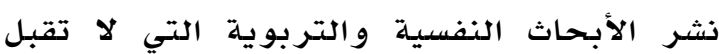

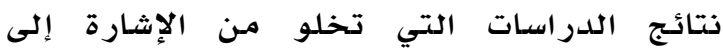
الدلالة العملية،. ويعتبر حجه الأثر (Effect Size) من أثهر الأسـاليب التي تستخدم لفحص الدلالة الده العملية، وهو أسلوب إحصائي كمي يقيس درجـة
توضيحي باستخدام بيانات افتراضية لتبيـان أسلوب تطبيق النموذج المقترح.

الدلالة الإحصائية (Statistical Significance) لقد ظهر مفهوم الدلالة الإحصائية منذ ثلاثمائة

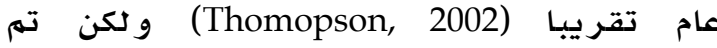

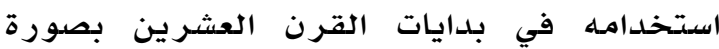
اكثر كثافة، وخاصة عند استخدام الاختبارات

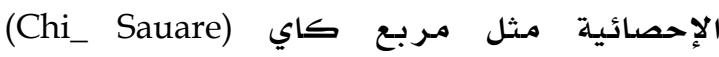
واختبار "ت" "، واختبسار تحليل التباين الاحادي

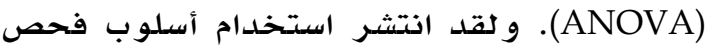
الدلالة الإحصائية للفرضيات الصفرية في الآونة الأخيرة بصورة متزايدة، وكان الهدف من ذلك هو اتخاذ قرار فيما إذا كانت النتائج التي تم التوصل إليها دالة إحصائيا أم غير دالة.

ويقوم هذا الأسلاوب على صياغة فرضية صفرية

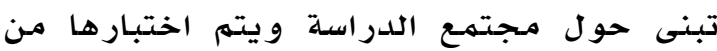
خلال بيانات عينة مـ المفترض انها تتشـابه في مئر

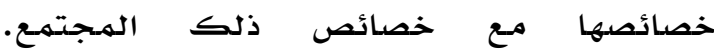
و يستخدم مفهوم مستوى الدلالة الفعلي لاختبار

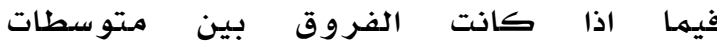
المهجموعات التجر يبية و الضابطة دالة إحصائيا ام

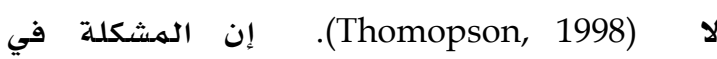
استخدام الدلالة الاحصائية تكمن في أنها لا تشير الهالير إلى الأهمية الفعلية للنتائج، وبالتالي لا يستطيع الباحثون تحديد درجه أهميه نتائجهم في سياق الهيه مـوضوع الدراسـة أو تبعا للظاهرة قيد الدراسلة الدئ إنها فقط تخبر فيها إذا كانت النتائج التي تم إنم الحصدول عليها تعود إلى عامل الصدفة أم لا. و في ضوء ذلك يستطيع البـاحث أن يتعامل مـع

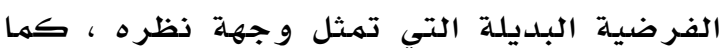
أنه في بعض الأحيان قد لا يكون قادرا على

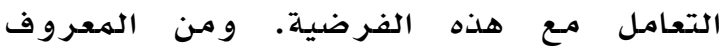
إحصائيا أن هذا النوع من الدلالة يتأثر بصورة مباشرة بحجهم العينة، بهعنى أن النتائج غير

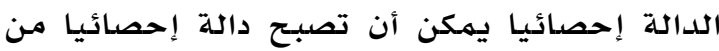
خلال زيادة حجم العينـة دون حدوث أي تغييير في خصائص التوزيع الإحصائي للبيانات الأصلية (قبل زيادة حجم العينة) وبالتالي يمكن القول

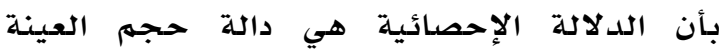


الأفضل، سواء كان ذلك في مجال الاضطر ابات العقلية أو صعوبات التعلهم أو حتى في مجال التشخيص و العلاج، ووفي هذا السياق يمكن القول أن فحص تأثير المعالجة او فعاليتها لا يعتبر

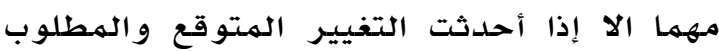
سواء في مجال التشخيص أو حتى في مجال إلى

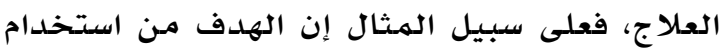

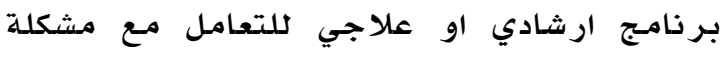

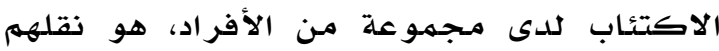
من حالة الاكتئاب إلى حالة من عدم الاكتئاب،

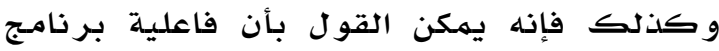
لتحسين مهارات القراءة لدى الاطفال تقاس من لن خلال قلدرة ذلك البرنامـج على نقل هؤلاء الأطفال من مستوى القراءة الضعيفة إلى مستوى الضى

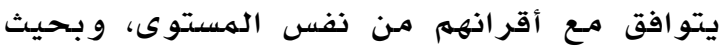

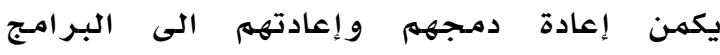

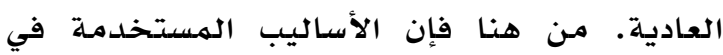
فحص الدلالة الإكلينيكية لنتائج الدراسات

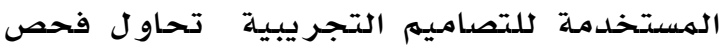
درجة فعالية الهمالجة المستخلدمة في إحداث

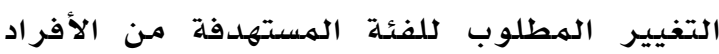
(Campbell, 2005) و هما في الهثاليين السـابقين: العملاء الذين يعانون من الاكتئاب، والأطفال ذوي المستوى الضعيف في القراءة، و ويعتبر (Jacobson, جاكبسون و فو لت وريفينس ستور روير" "Follette, Revenstorf, 1984) أسلوبا محددا لفحص الدلالة الإكلينيكية للنتائج. ويعود السبب في اهتمام هؤلاء الباحثين

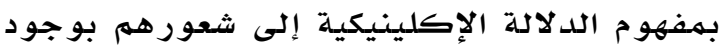
نقص ما في ميدان الدراسـات التي تهتمر بهـهال

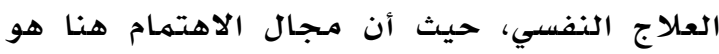

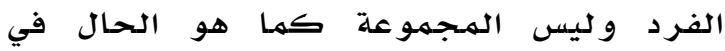

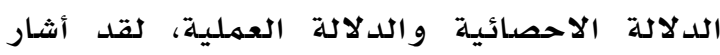
هؤلاء الباحثين ) Jacobson, Follette, Revenstorf, 1984) إلى أن الفرق بين المت المتوسطات لا يعطي

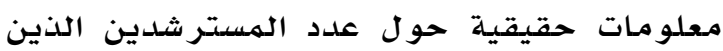

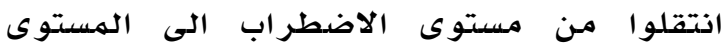

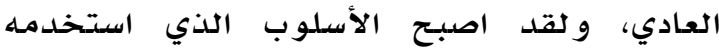

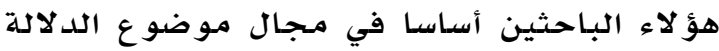

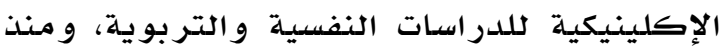

أهمية المعالجة مـن خلال فحص الفرق بين المتوسطات بغض النظر عن الدلالة الإحصائية لتلك الفروق، وبمعنى آخر فقد تكون النتائج

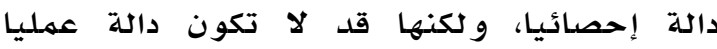
(Thompson, 2006). هناك عدة أساليب لاستخدام حجم الأثر، فعلى سبيل الهثال هناك ما يسهى: حجم الأثر الهعدل (Corrected Effect Size) وهناك أيضا أساليب تعتمد على فحص الفروق الفر

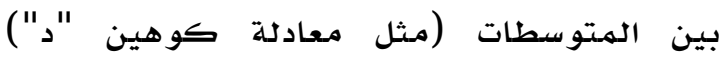
وهناك أساليب تستخدم نسبة التباين الذي رهي يفسره الهتغير المستقل من تباين الهتغير التابع

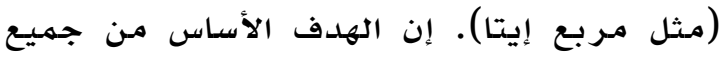
الأساليب السابقة هو الإجابة على السؤال التالي:

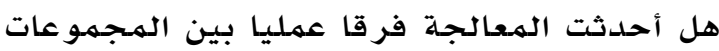
التجريبية و الضـابطة، و ما مقدار الفرق الذي لهي حققتهى ويعتبر أسلوب حجم الأثر مفيدا لأنه يهتهم بتقرير أهمية النتائج على المستوى العملي وهو بذلك يتعدى مفهوم الدلالة الإحصائية التي تهتم فقط فيما إذا كانت النتائج تعود إلى عامل بل

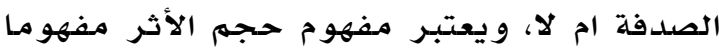
مهما في الدر اسـات النفسية و التربوية ، و في هذا

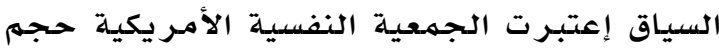

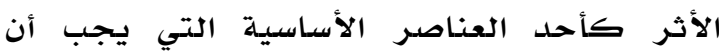

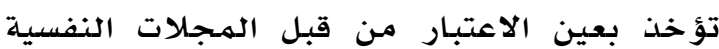
لقبول نشر تلك الدرراسات أو رفضها .(Wilkison \& APA Task Force on statistical Inference, 1999)

الدلاكة الإكلينيكية (Clinical Significance): إن معظم الأساليب الهستخدمة في تقدير حجم

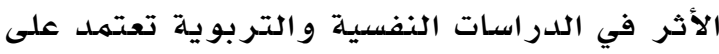

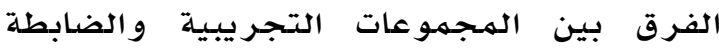
بلدون أن تهتم بذلك التغير الذي يتهم على النى مستوى الفرد الواحد. و هناك اتجاه حديث في لفي

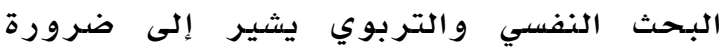
قياس ورصد مستوى التغيير الحاصل نتيجة

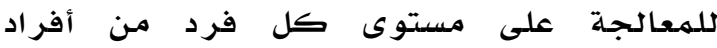

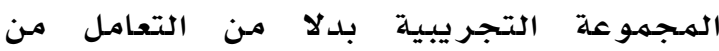

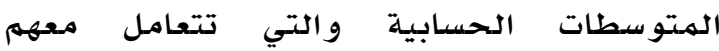

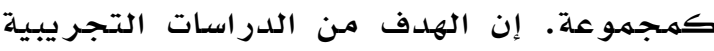

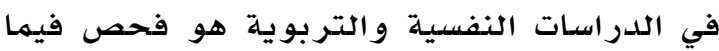
اذا كانت الهعالجة تسـاعد الناس على التغير نحو 
هذا الغرض تم حساب حجم الأثر باستخدام

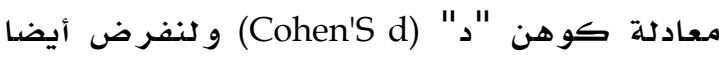
ان كلا الدراستين اشارت أن مقدار حجم الأثر باستخدام المعادلة المشار إليها يساوي (0.9)، و بالرجوع للمعايير التي أشار إليها كوهن، فإنه يمكن و صف تلك القيمة بأنها كبيرة جدا، مـا يشير إلى أن الفرق بين متوسطات الدرجات البعدية للمجهو عتين: التجريبية، والضابطة في كلتا الدراستين كانت ظاهرة وو اضحة وتشير الى وجود دلالة عملية للنتائج في كلا

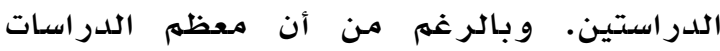

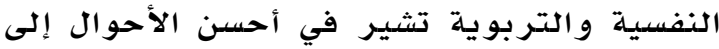

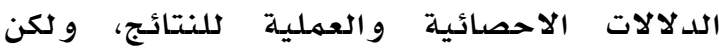
و للاسف، فإن الدراسـات التي تشير الى الى الدلالدة الديه

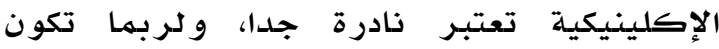
معدو مـة على مستوى الوطن العربي. وبالرجوع

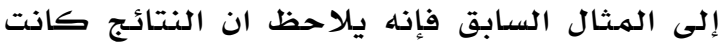
دالة إحصائيا في الحالتين، و أنها كانت أيضا دالة الهاليال عمليا و بنفس المستوى، فهل هذا يعني أنه يمكن للباحث استخدام أي مـن الأسلوبين على اعتبار انهما يحققان نفس النتائج؟ قبل الإجابة على هذا الها السؤال، لنفرض ان الباحثين في تلك الدرراسات

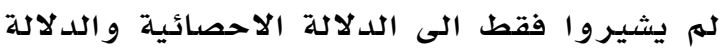
العملية بل أنهم ايضا أشاروا إلى الدلالدئل الإكلينيكية في نتائجهم، في هذه الحالة فإنه يمكن ان نجد فروقا بين نتائج كلتا الدراستين،

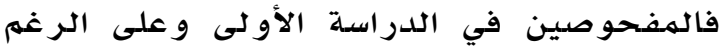

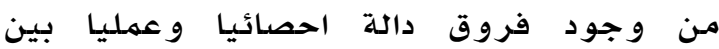

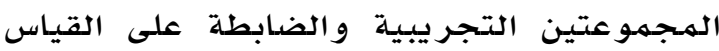

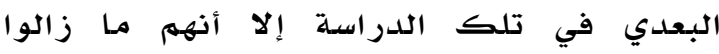
يعاذون من مشكلة الاكتئاب تبعا لدرجاتهم على إلى

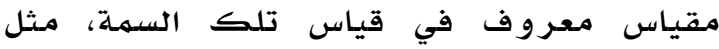

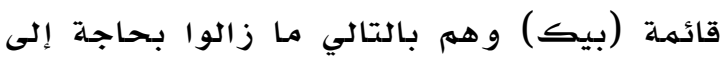
العلاج حتى يصلوا الى حالة من عدم الاكتئساب، و في الهقابل إذا أشارت نتائج الدلادة الإكلينيكية

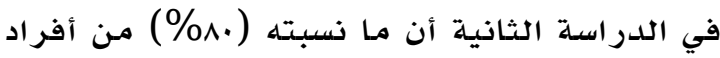

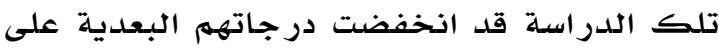
مقياس الاكتئاب بصورة كافية بحيث انهم

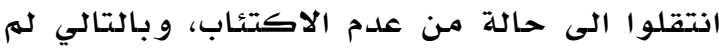
يعودوا بحاجة الى اية معالجة. و بناء على نتائج
ذلك الوقت ظهرت العديد مـن الأساليب الأخرى

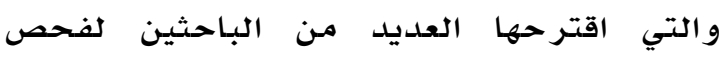
الدلالة الإكلينيكية وبحيث أصببح مفهوم الدلالنة الإكلينيكية أحد المؤشرات الرئيسية في تحديد

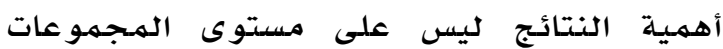
فقط بل أيضا على مستوى الافر اد، ولقد أحدث هذا المفهوم نقلة نوعية في مـجال البحث النفسي والتربوي تجاوزت في الحقيقة مفهومي أو

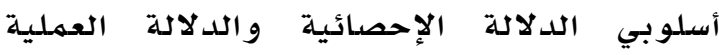

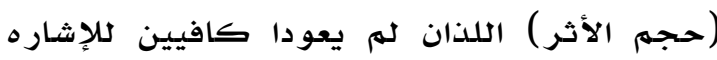
الى اهمية النتائج في الدراسـات التجر يبية. ولهر ولكن

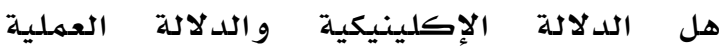
مفهومان متر ادفان أم أن هنالك فرق بينهماء. بما لها أن مفهوم الدلادة الإحصائية مفهوم جديد نسبيا

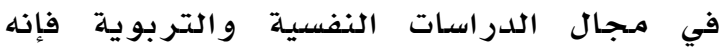
يتداخل في كثير من الأحيان مـع مفهوم الدلادلة العملية للنتائج، حيث يتم في كثير من الأحيان الخلط بين كال النوعين (Peterson, 2008)، و في الحقيقة فإن الدلالة الاكلينيكية تختلف تماما عن الدلالة العملية، والمثثالين التاليين يوضحان

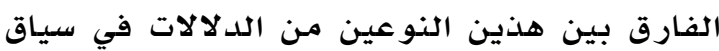

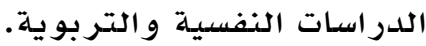

مثال نفسي: لنفرض أنك أخصائي نفسي و تعمل

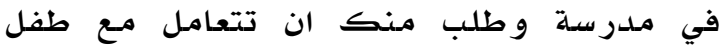
يعاني من مشكلة الاكتئساب، وعند البحث في الأدب وجدت دراستين تقدم كل منهما أسلوبا علاجيا مقترحا لحل مشكلة الاكتئاب لدى لدى لدابل

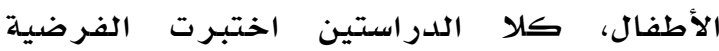
الصفرية التالية: لا توجد فروق دالة إحصائيا

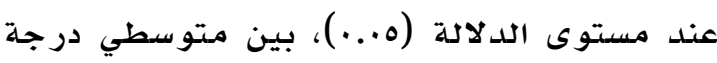
الاكتئاب على القياس البعدي للمهجموعتين التجر يبية و الضابطة، لنفرض ضان نتائج كل من الن

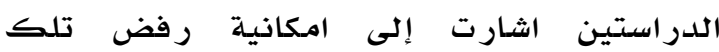
الفرضية الصفرية حيث كانت قيمهة مستوى

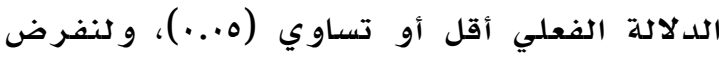
انها كانت تساوي (r...)، في هذه الحالة يمكن الاستتـاج ان كالا من الأسلوبين المستخدمين في علاج مشكلة الاكتئاب لدى الأطفال كانا فعالين، و لنفرض أيضا أن الباحثين في الدراستين اهتموا

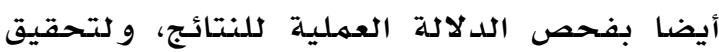


بعد البرنامـج كانت أكثر من عدد الكلمات التي

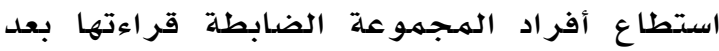

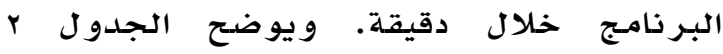

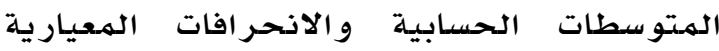
لعدد الكلمات التي استطاع أفراد المـجمو عتين

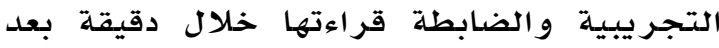

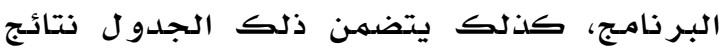

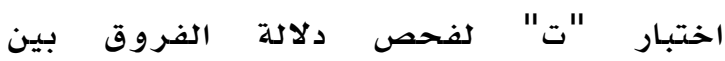
المتتو سطين.

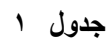

عدد الكلمات التي استطاع أفراد الدراسة قراعتها بطريقة صحيحة خلال دقيقه

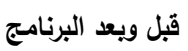

\begin{tabular}{|c|c|c|c|}
\hline \multicolumn{2}{|c|}{ عدد الكلمات } & \multirow[t]{2}{*}{ المجموعة } & \multirow[t]{2}{*}{ الاسم } \\
\hline بعد البرنامج & قبل البرنامج & & \\
\hline 7. & $\varepsilon$. & التجريبية & محمد \\
\hline$\varepsilon V$ & ro & التجريبية & عمر \\
\hline 70 & $\leqslant 0$ & التجريبية & حمزة \\
\hline$\varepsilon\rceil$ & rᄉ & التجريبية & سوسن \\
\hline r & $r V$ & التجريبية & صفاء \\
\hline$r \varepsilon$ & $r$. & الضنابطة & علي \\
\hline$\varepsilon\rceil$ & $\varepsilon$. & الضنابطة & قصي \\
\hline rt & 11 & الضنابطة & زين \\
\hline$r \cdot$ & $r \leq$ & الضابطة & سلمى \\
\hline r. & r. & الضابطة & فاطمة \\
\hline
\end{tabular}

عدد الكلمات التي استطاع أفراد المجموعتين التجريبية والضابطة قراعتها

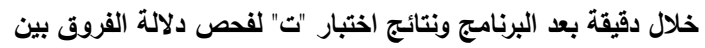

\begin{tabular}{|c|c|c|c|c|c|c|}
\hline \multicolumn{7}{|c|}{ المتوسطين } \\
\hline مستوى & درجات & قيمة & الاتحراف & المنتوسط & العدد & المجموعة \\
\hline الدلالة & الحرية & " " & المعياري & الحسابي & & \\
\hline \multirow[t]{2}{*}{$\ldots+r$} & $\wedge$ & r.A^ & 14.91 & 0. & 0 & التجريبية \\
\hline & & & $1 . . r \Lambda$ & YA.T & 0 & الضابطة \\
\hline
\end{tabular}

إن نتائج اختبار "ت" في جدول r ب تشير إلى وجود فروق دالة احصائيا عن مستوى الدلالة إديار

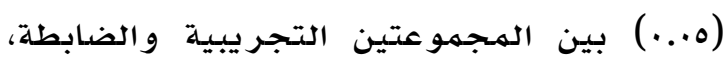
لكن هذه النتائج لا تعتبر كافية لتحديد درجيد

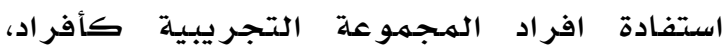
و ليس كمجموعة، من البرنامسج وبالتالي فإنها

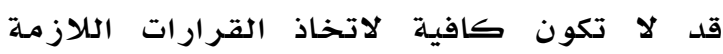
لتحسين مهارة القراءة لدى هؤلاء الأفراد.

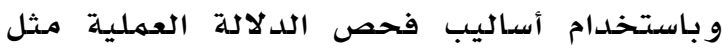

الدلالة الإكلينيكية المشار إليها في كلتا

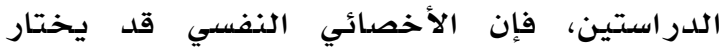
الطريقة الثانية لأنه أكثر فاعلية الاحية من الناحية الإكلينيكية من الأسلوب الهستخلدم في الدهابه الدراسلة

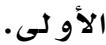

ثانيا: مثال تربوي، لنفرض أن مدير مدرسة

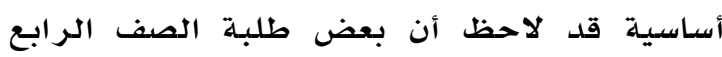

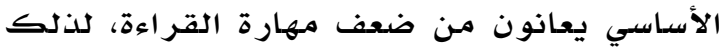

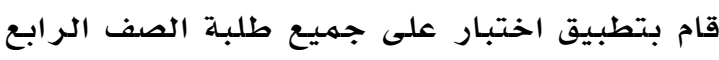

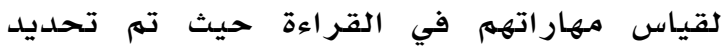
درجة القطع له كلمهة في الدقيقة كمعيار للحكم فيما اذا كان الطفل متقنا أو غير متقنا لههارات القراءة، وفي ضوء ذلك تهم تحديد

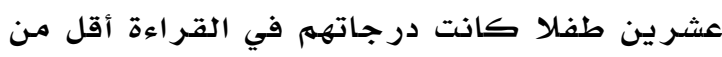
0، وهم بالتالي بحاجة لتدخل المـدرسة لتحسين

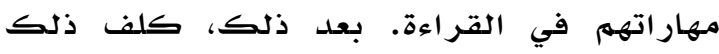
الهمدير أحد معلمي اللغة العربية باختهيـار عشرة

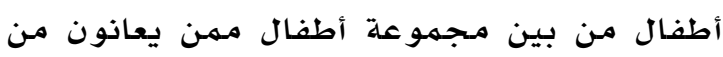

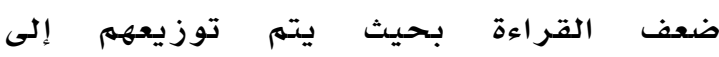

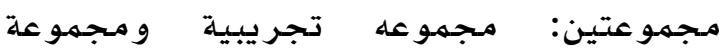

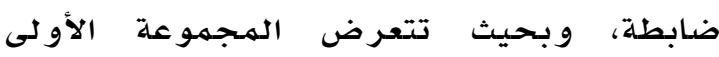
لبر نامسج تدريبي مكثف لمدة أربع أسابيع يهدف إلى تحسين مهارات الأطفال في القراءة بينهما له

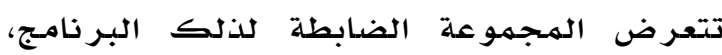

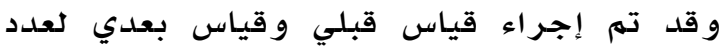
الكلهمات التي يستطيع أطفال كلتا الهـجموعتين قر اءتها قبل وبعد تنفيذ البرنامـج، ويشير جدول الدول

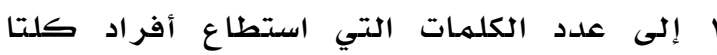

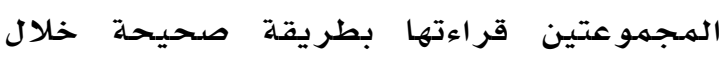
دقيقة.

و باستخدام اختبـار "ت" للعينات المستقلة لفحص

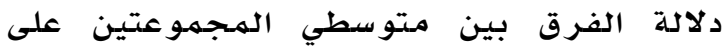

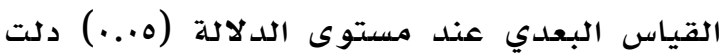
نتائج هذا التحليل إلى وجود فروق دالة احصائيا بين متتوسط عدد الكلمات التي استطاع أطفال

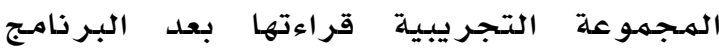

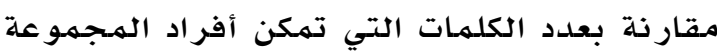

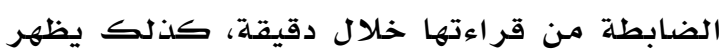
من خلال المتوسطات الحسابية ان عدد الكلمـات

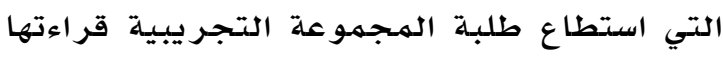


طرق تقدير الدلالة الإكلينيكية في الدراسات

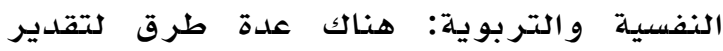
الدلالة الإكلينيكية وفي الدراسة الحالية تهم

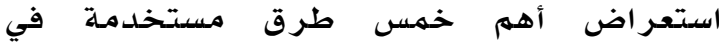

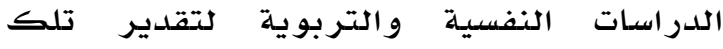
الدلالة. و هذه الطرق هي طريقة جاكبسون-

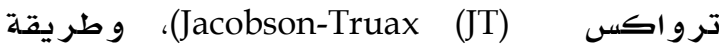

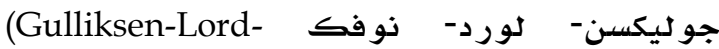

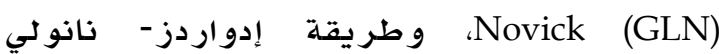
(Edwards-Nunnally (EN)

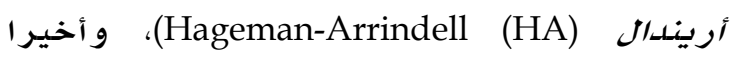
الطريقة الخطية الهر مية Hierarchical Linear) Bauer, Lambert, \& Nielsen, )Method (HLM)

ومـن الجدير ذكره أنه تم في الدراسـة الحالية

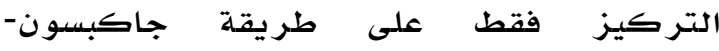
ترواكس (Jacobson-Truax (JT) لسببيين, أو لا: لأن هذه الطريقة هي الأكثر استخداما في

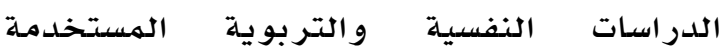
للتصاميهم التجر يبية وخاصدة تلك الدر اسـات التي يكون الهدف الأساس منها هو إحداث تغيير عند الأفر اد نتيجة لتعرضهم لهعالجة محلددة، و ثانيا: لأن هذه الطريقة- على الرغم مـن بساطتها- فهي

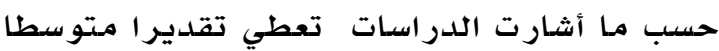
لأثر المعالجة بمعنى أنها لا تقلل و لا تضخم في

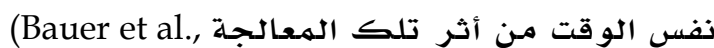
.2004)

من جهة ثانية فإن الدراسة الحسالية تسعى لتقديم عرضا مختصرا للطرق الأخرى التي تم ذهر ذها

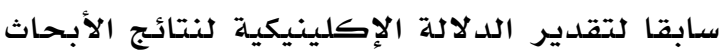
التجريبية حيث أن الهاف مـن ذلك توفير عدد

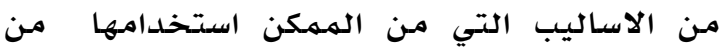
قبل الباحثين العرب وخاصدة أن هذا المفهوم و على الرغم من أنه قد ظهر منذذ عام ع19 إلا أإنه لهم يشر إليه بصورة كافية في الدراسـات النفسية والتربوية والتي تم إجر اءها في البيئة العر بية.

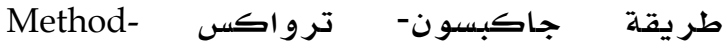
(Jacobson-Truax (JT)
اختبـار كوهين "د" فإننا نحصل على حجم أثر

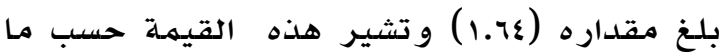

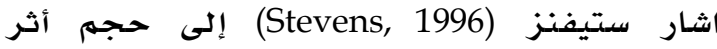
كبير • كما وتشير قيمة مؤشر حجم الأثر هذه أنها إلى أن البرنامـج التدريبي قد أحدث فرقا دالا مـن

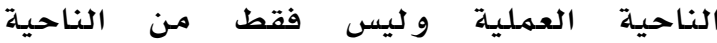
الإحصدائية بين المبجمو عتين التجر يبية و الضابطة من حيث عدد الكلمات التي استطاع الأطفال في

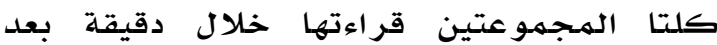
البر نامـج. وتكمـن أهمية مؤشر حجم الاثر إلى

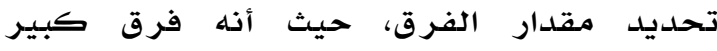
وواضـح. ولفهم فاعلية البرنامـج بطريقه أكثر عمقا وأكثر تفصيلا، خاصدة من حيث تأثيرها

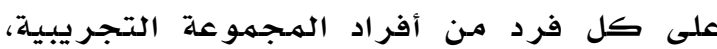
فإنه من الضروري تقدير الدلالة الإكلينيكية آخذين بعين الاعتبار أن نقطة القطع التي تميز

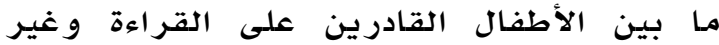

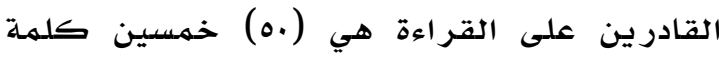
في الدقيقة، و باستخدام هذا المعيار و بالرجوع للبيانات الواردة في جدول ا يتضح أن اثنين

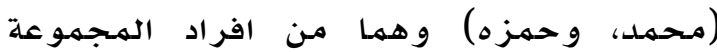
التجريبية لهم يتحسنا فقط في القراءة، بل انهما

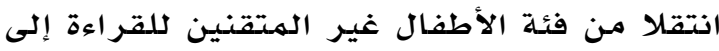

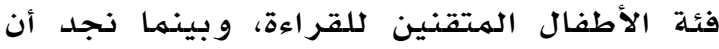

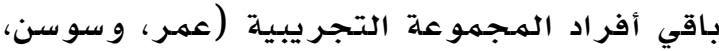

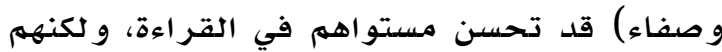

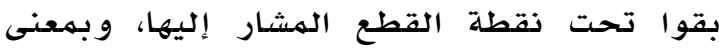
آخر أنهم لهم ينتقلوا الى فئلة الطلاب المتقنين للقراءة. و من المـلاحظ أيضا من خلال لهم البيانات

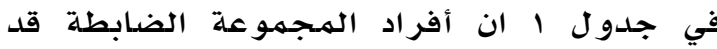

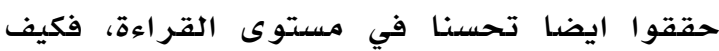
يمكن تفسير حلدوث ذلك في غياب تعرضهم للبرنامـج التدريبي؟ وقد يعود السبب في ارتفاع

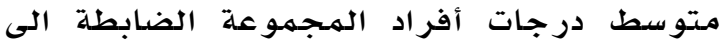
عامل الانحدار نحو الهتوسط، فكما هو معروف

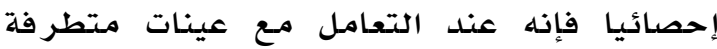
على سمة ما، فإنه يلاحظ ان متوسط القياس

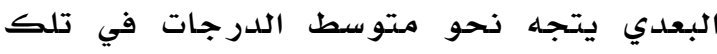
السمـة، وهذا ما يعرف احصائيا بالانحدار نحو 
و بمعنى آخر ، فإنه يمكن استخراج نقطة القطع أ

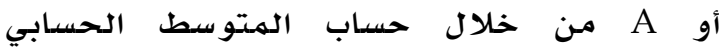

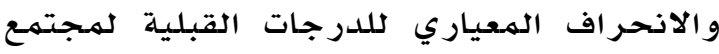

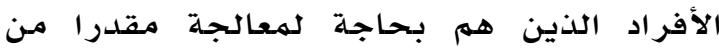

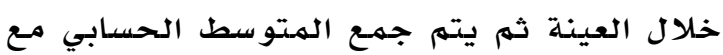
ضعف قيمة الانحر اف المعياري للدرجات نفس

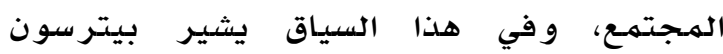
(Peterson, 2008) درجة في القياس البعدي يجب أن تكون خارج

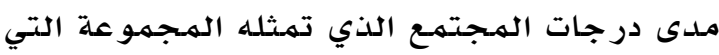

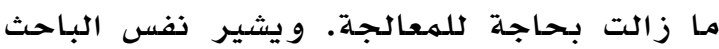
إلى أن الدرجة ب أو B هي درجة في التهاس القياس

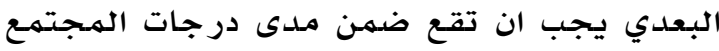

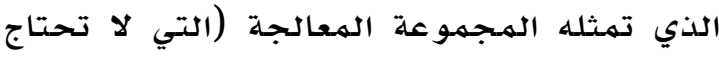

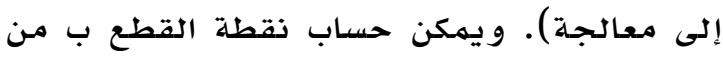

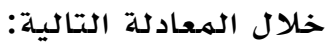

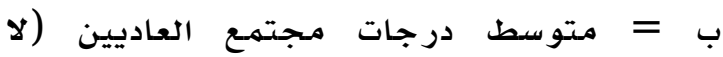
يحتاجون لمعالجة) + r X الانحر اف المعياري

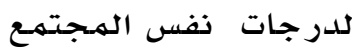

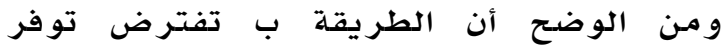
معلومات حول توزيع درجات الأفراد العاديين على السمة قيد الدراسـة وفي حال عدم توفر مثل لورل

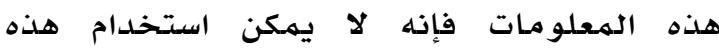

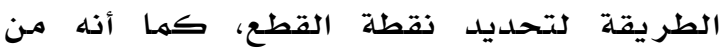
السهل نسبيا على معظم المسترشدين تجاوز هذه النقطة و ذلك بسبب أنه في كثير مـن الأحيان

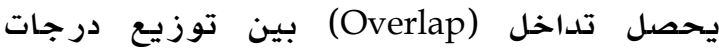

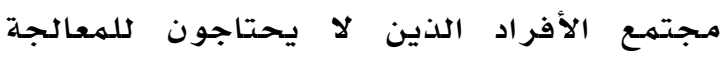
(العاديين) و توزيع درجات مجتمع الأفر اد الذين يحتاجون للمعالجة البع دورين

.(2004)

أما بالنسبـة لنقطة القطع ج أو C فهي تلك الدرجة البعدية التي يجب ئه أن تكون أقرب

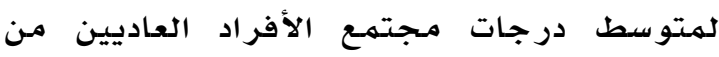

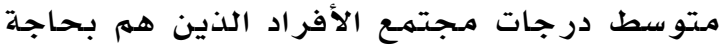
لمعالجة (Peterson, 2008)، أو هي تلك الو الدرجة

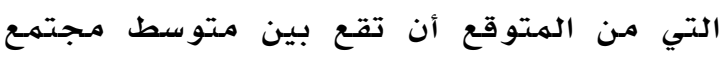
العاديين و مسجتمـع الأفر اد الذين بحاجـة للمعالجهة.

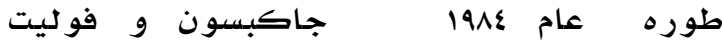
وريفنستورف (ر) ) Jacbson, Follett, \& Revenstrof, 1984) هو الطريقة الأساسية لتقدير الدلالة الإكلينيكية في الدراسـات النفسية والتربوية. و لقد تم مراجعة هذا الأسلوب من قبل كل من من الإسل جاكبسون و ترواكس ( Jacobson and Truax,

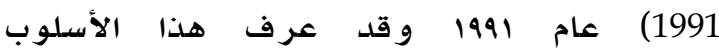
بــريقة جي تي (JT Method). و يعتمد هذا الأسلوب على خطوتين أساسيتين حيث يتم في البداية تحديد درجة تسهى بنقطة القطع ( Cut

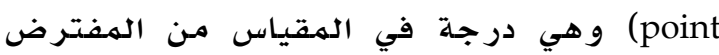
أنها تكون قادرة على أن تميز بين الأفر اد الذين

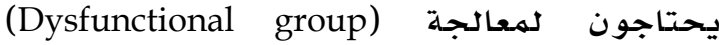
والأفراد العاديين أو الذين لاجو يحتاجون لنفس الهعالجة (Functional group)، بينهما يتم في الخطوة الثانية تقدير ما يسهى بمؤشر ثبات

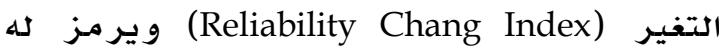
بالرمز (RCI) و في ضدو هذين المعيارين يتم تصنيف أفراد عينة الدراسات إلى أربعة فئات:

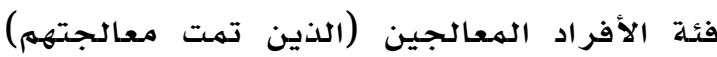

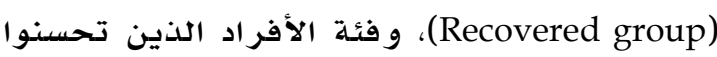

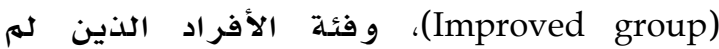
يحدث لهم أي تغير (Unchanged group)، و فئة

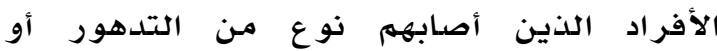

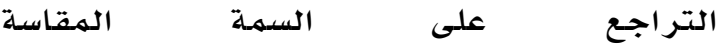
(Deteriorated group)

بالنسبـة لطرق تقدير نقطة القطع في هذا الأسلوب فإن هناك ثلاث أسـاليب لتحقيق ذلك حسب ما يشير بيترسون (Peterson, 2008) و يشار في الأدب إلى هذه الطرق بما يسمى بالطريقة أ

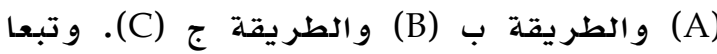
للطريقة أ فإنه يمكن تحديد درجـة القطع من

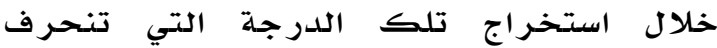
بهقدار درجتين معياريتين عن متوسط الدرجات

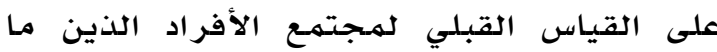
زالو بحاجة لمعالجة \& \&auer, Lambert, \& .Nielsen, 2004)

أ= متوسط الدرجات القبلية (لمجتمـع الأفراد

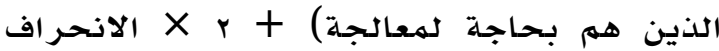

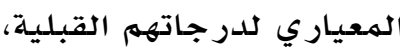




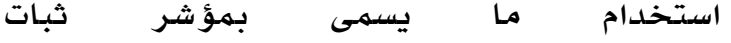

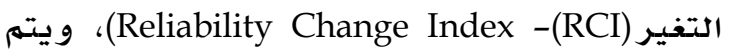
حساب قيمة هذا المؤشر لكل فرد فلى ملى حدة وذلك من خلال حساب الفرق بين درجاته على

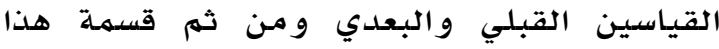

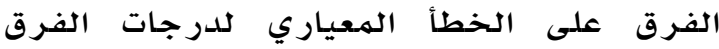

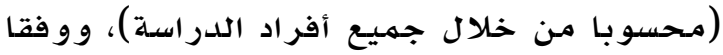
لهذا الأسلوب فإن قيمـة مؤشر ثبات التغير قد قد

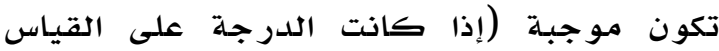

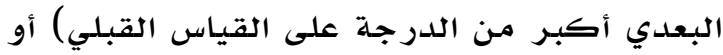

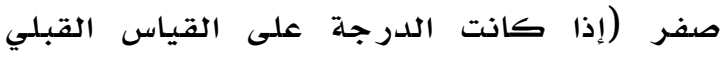

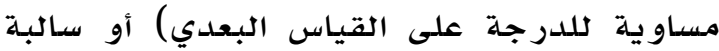

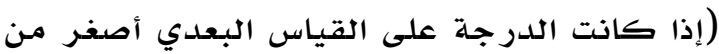

$$
\text { الدرجة على القياس القبلي). }
$$

ومـن خلال استخدام درجة القطع و مؤشر ثبات

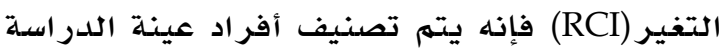
إلى أربع فئات وهي: فئسة الأفراد المعافيين

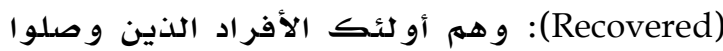
لحالة الشفاء وله يعودوا بحاجة لاي معالجة، لهات ويعرفوا وفقا لطريقة طريقة جاكبسون-

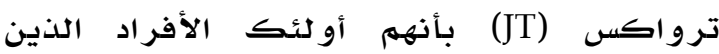

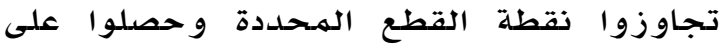
مؤشر ثبات تغير ذو قيهمة موجبة، ووفئلة الأفراد الذين تحسنوا (Improved): وهم أو لئك الأفر اد الذين تحسنت دجاتهم البعدية مقارنة بدرجاتهم

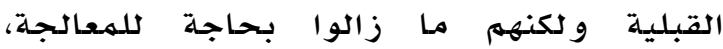
ويعرفوا وفقا لطريقة طريقة جاكبسونترواكس (JT) بأنهم أولئك الأفر اد الذين للم يتجاوزوا نقطة القطع المحددة ولكنهم حصلوا على مؤشر ثبات تغير ذو قيمـة موجبة، وفئة الأفر اد الذين لهم يتغيروا (Unchanged): وهم موسئر أولئك الأفراد الذين لهم يحدث أي تغير لديهم

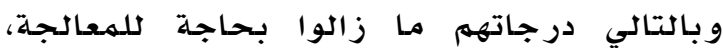
ويعرفوا وفقا لطريقة طريقة جاكبسون-

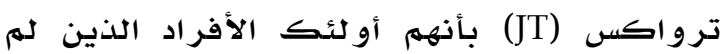
حصلوا على مؤشر ثبات تغير يساوي صفر نتيجة كتساوي درجاتهم القبلية مـع درجاتهم

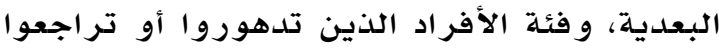

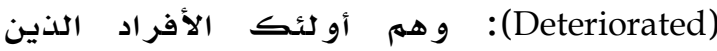
كانت درجاتهم البعدية أقل من درجاتهم القبلية
ويمكن حساب هذه النقطة باستخدام المعادلة التالية (Bauer, Lambert, \& Nielsen, 2004): بلدئ

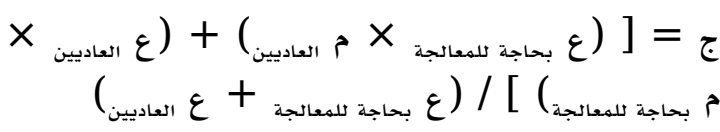
حيث: ع بحاجة للمعالجة: الانحر اف الهعياري لدرجات

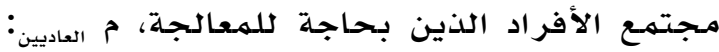

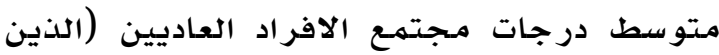

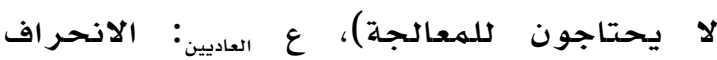
المعياري لدرجات مجتمـع الافر اد العاديين (الذين

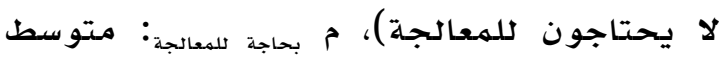

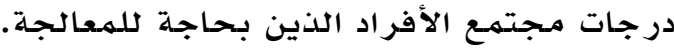
و تعتبر الطريقة السابقة في تقدير نقطة القطع هي الأسلوب الأفضل في حال توفر معلومـات عن توزيع درجات مجتمهع الأفراد العاديين (الذين لا لادئ

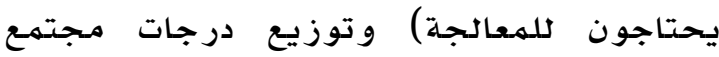

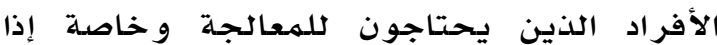
Bauer, كان هناك تداخلا بين التوزيعين (Lambert, \& Nielsen, 2004) الطريقة في تقدير نقطة القطع تعتبر أكثر دقة من الطريقتين السابقتين خاصدة أنها تعتمدد على الاحتمالية النسبية لدرجة ما يتم الحصول عليها من خلال مجتمـع محددد في مقابل مـجتمـع

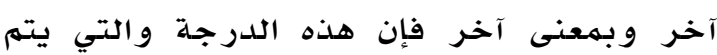
الحصول عليها من خلال الخصائص الإحصدئية

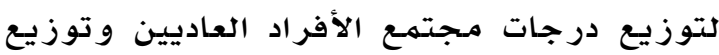

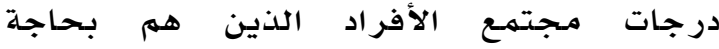
للمعالجهة، مها يجعلها نسبيا الأكثر دقة دقة مقارنة

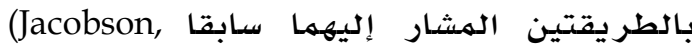
Roberts, Berns, \& McGlinchey, 1999) المقابل يعتبر استخدام الطريقتين أ و ب أو A و و أكثر منطقية في حال عدم توفر البيانات B

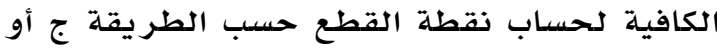

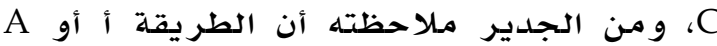
تعتبر هي الأفضل في حال عدم توفر بيانات كافية حول طبيعة توزيع درجات مجتمهـ الأفراد العاديين و مهجتمـع الأفر اد الذين بحاجـة للمعالجـة. وبعد أن يتم تحديد نقطة القطع ووفقا لأي من الأسـاليب السـابقة، فإن الخطوة التالية هي تحديد مقدار التغير الذي حدث وذلك من خلال 
و كان مؤشر ثبات التغير لديهما موجبا. أما

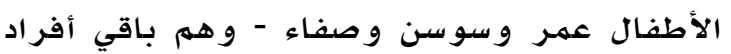

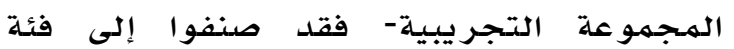

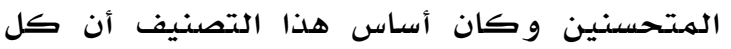
منهم قد حصل على مؤشر ثبات تغير موجب و لكنهل فشل في تجاوز نقطة اقطع مـن حيث عدد

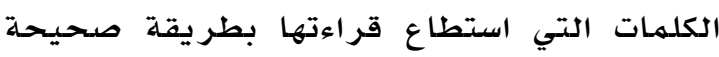
خلال دقيقة في القياس البعدي.

أما بالنسبة لتصنيف أفراد المجموعة الضابطة، فكما يتضح في جدول r فإن ثلاثة من أفرادها وهم علي وقصي وزين قد صنفوا أيضا إلى فئة

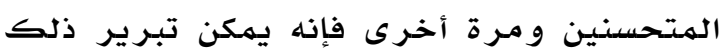
التحسن من خلال مبدأ إحصائي معروف وهو انحدار القيم ذحو المتوسط، و لتوضيح ها المبدأ لنفرض أن .1 طالب قد تقدموا لإختبار مكون

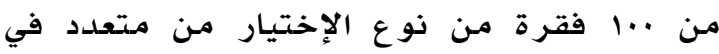

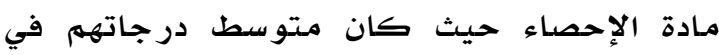

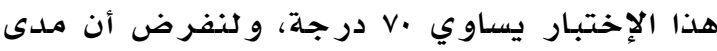

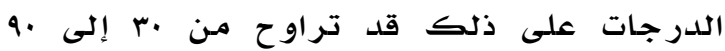

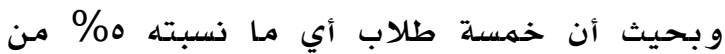

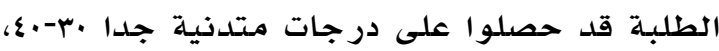

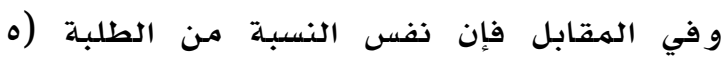

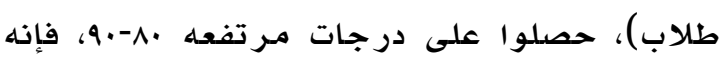
من المتوقع إحصائيا في هذه حالة تطبيق اختبار

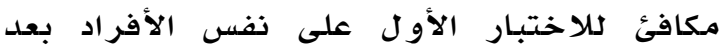

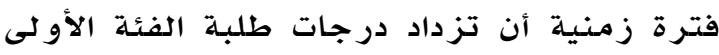

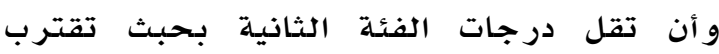
درجات طلبة هاتين الفئتين من متوسط الدر جـات

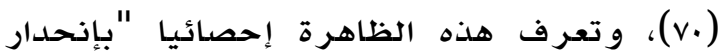

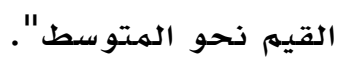

و بالر جوع إلى نتائج جدول r يلاحظ أن الطفلة فاطمة- وهي من افر اد المجمموعة الضـابطة- قد صنفت إلى فئة الثابتين (له يحصل لديهم تغير الدير في السمة المقاسة) وركان أساس هذا التصنيف أن درجـة هذه الطالبة على القياس القبلي قد القد

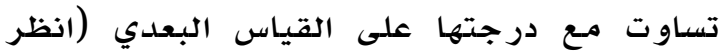

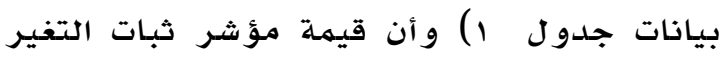

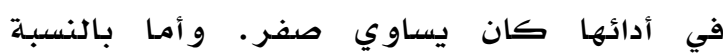

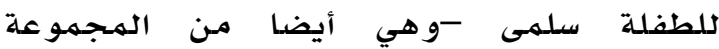

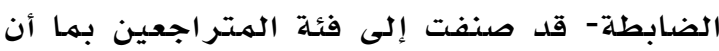

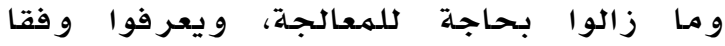

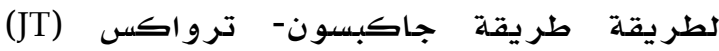
بأنهم أولئك الأفراد الذين لهم يتجاوزوا نقطة القطع المحلددة وحصلوا على مؤشر ثبات تغير ذو قيمهة سـالبـة.

و لتوضيح كيفية تقدير الدلالة الإكلينيكية و فقا لطريقة طريقة جاكبسون- ترواكس فيس (JT) فإنه سيتهم الرجوع إلى البيانات المشار إليها في

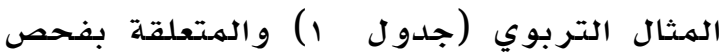
فعالية برنامه تلدريبي في تحسين مهارات

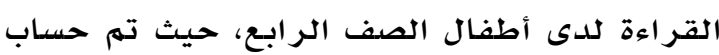

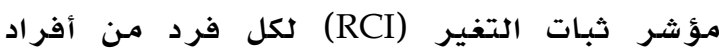
الهمجمو عتين التجريبية والضابطة وباستخدام

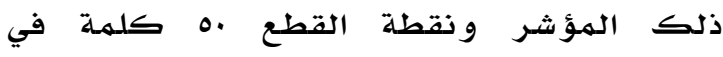
الدقيقة تم تصنيف كل فرد من أفراد الدراسلة

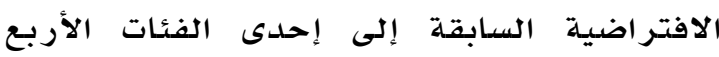

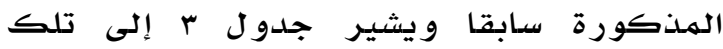
النتائحج

جدول r

تصنيف أفراد العينة في الاراسة الافتراضية والمتعلقة بتحسين

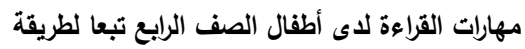

\begin{tabular}{|c|c|c|c|c|}
\hline \multicolumn{5}{|c|}{ جاكبسون - ترواكس (JT) } \\
\hline التصنيف & مؤشر & 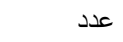 & المجموعة & الاسم \\
\hline 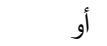 & 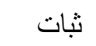 & الكلمات في & & \\
\hline وصف & التغير التغر & القياس & & \\
\hline التغير التغر & $(\mathrm{RCl})$ & البعدي & & \\
\hline 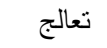 & 7.19 & 7. & التجريبية & محمد \\
\hline تحسن & $V .01$ & $\varepsilon V$ & التجريبية & عمر \\
\hline تعالج & 7.19 & 70 & التجريبية & حمزة \\
\hline تحسنت & T.Y. & $\leqslant 7$ & التجريبية & سوسن \\
\hline تحسنت & I.VT & rt & التجريبية & صفاء \\
\hline تحسن & $1 . \Gamma \Lambda$ & $r \varepsilon$ & الضابطة & على \\
\hline ت تحسن & r..V & $\leqslant 7$ & الضابطة & قصي \\
\hline تحسن & $1 . V T$ & rT & الضابطة & زين \\
\hline تراجع & $1 . r \wedge-$ & $r \cdot$ & الضابطة & سلمى \\
\hline ثبت أو & $\cdots$ & r. & الضابطة & فاطمة \\
\hline ل لم يتغير & & & & \\
\hline
\end{tabular}

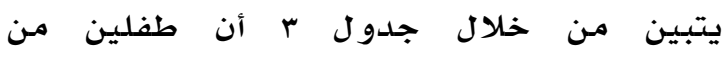

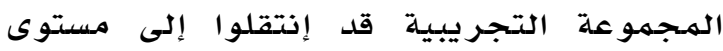

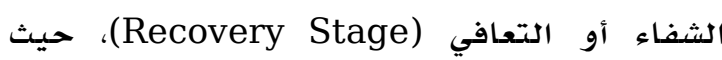
يلاحظ أن الطفلين محمد وحمزة قد تجاوزا نقطة القطع المحددة و هي .0 كلمسة في الدقيقة 
الطريقة قد تتأثر بإنحدار القيم نحو الوسط، و بناء على ذلك قدم سبير (199ץ) طرقة أخرى لتقدير الدلادة الاكلينيكية تعتمد على الأفكار التي قدمها كل من إدواردز (Edwards, 1978)

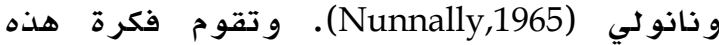
الطريقة بصورة أساسية على تعديل الدرجات

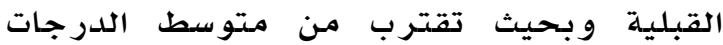
القبلية وبمعنى آخر فإن الدرجة القبلية للفرد

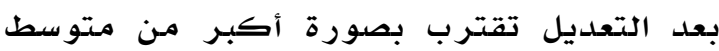

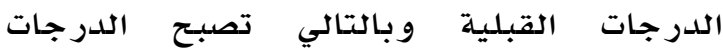
القبيلية أكثر تجانسا وبالتالي يقل تأثير عامل انحدار القيم نحو الوسط خاصلة في حالة القيم المتطرفة، أما الخطوة التالية تبعا لطريقة إدواردز - نانو لي (EN) فتتمثل بتقدير التغير في أداء الفرد و ذلك بإستخدام طريقة فترة الثقة اعتمادا لعلى (Confidence Interval method) الدرجة القبلية المعدلة بلدالا من الدرجة الهـلاحظة. وهنا تشير بيترسون (Peterson, ) 2008 إلى أن استخدام أسلوب فترة الثقة يتطلب فرقا أكبر بين القياسين القبلي والبعدي للفرد من ذلك الفرق والذي يتهم الحصول عليه من خلال طريقة جاكبسون- ترواكس حتى يعتبر دال إكلينيكيا.

طريقة هيجمان- آريندال Hageman-Arrindell) إقترح كل هن هيجمان و آرينديل (Hageman and Arrindell, 1999)، ضرورة القيام بإجراء تعديلين أساسيين على الطريقة التي قدمها جاكبسون و ترو اكس (Jacobson and) و ويتمثل التعديل الأول Truax- (JT), 1991) بضرورة استخدام أساليب إحصائية مختلفة

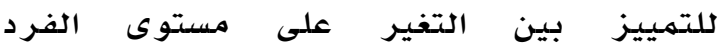

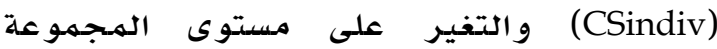
بصورة أكثر وضوحا. أما التعديل (CSgroup) الثاني فيتضهن الإتفاق مـع هاسو (Hsu, 1999) وسبير (Speer, 1992) فيما يتعلق بوجوب معاف تعديل

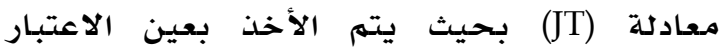
مشكلة إنحدار القيم نحو الوسط. و لحل هاتين المشكلتين اقترح

و آرينديل(Hageman and Arrindell, 1999)

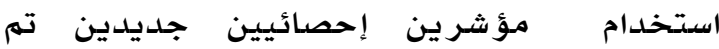

درجتها على القياس البعدي كانت اقل من درجتها على القياس القبلى (انظر بيانات جدول 1) كما أن مؤشر ثبات التغير لدى هذه الطيات الطالبـة

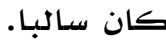

(Gulliksen- طريقة جوليكسن- لورد- ذوفك :Lord-Novick (GLN)

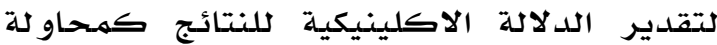
لتجاوز أو لتصحيح الخطأ الذي وقعت به (Jacobson- - طريقة جاكبسون- ترواكس اونس وذلك من وجهة نظر بعض Truax (JT) الاحصدئين مثل العالم هاسو (Hsu,1999)، حيث أشار هاسو أن استخدام هذه الطريقة للفرق بين الدرجات القبلية والدرجات البعدية في تحديد قيمة معامل ثبات التغير (RCI) لهم ير اعي و يضع بعين الاعتبار احتمال انحدار القيم نحو الوسط،

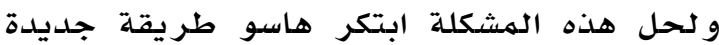
لتقدير الدلالة الإكلينيكية اعتمدت بصورة أساسية على بعض الطرق الإحصائية والتي قدمها العاله جو ليكسين (Gulliksen, 1950) في عام Lord and Novic, ) و العالمان لورد و نو فك 190.

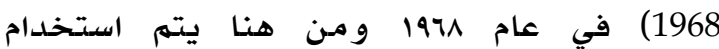
الاختصار (GLN) عند الإثارة لهذه الطريقة في تقدير الدلالة الإكلينيكية. وووفقا لطريقة فإنه يجب في البداية استخدام متوسط ولئه

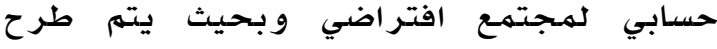

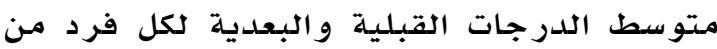

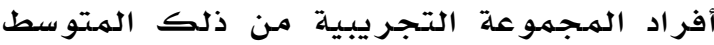
و ذلك كأسلوب لحل مشكلة انحدار القيم نحو الوسط، و وكذلك فإنه وفقا لهذه الطريقة

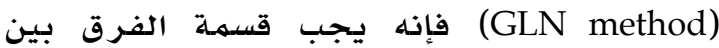
القياسين القبلي والبعدي على الانحر اف

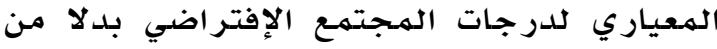

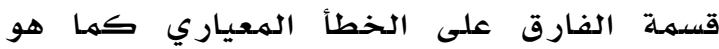

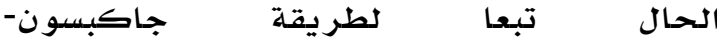
ترو اكس(Peterson, 2008). تحمال

وطريقة إدواردز - نانو لي Edwards-Nunnally (EN): إنتقد العالم سبير (Speer, 1992) طريقة جاكبسون- ترواكس (JT) لنفس السبب الذي أشار إليه هاسو (Hsu, 1999) وهو أن هذه 
الحقيقية إن الحسابات المستخدمة في هذا الأسلوب هعبة نسبيا لذلك فإن هناك برامج إحصائية خاصدة من الضروري استخدامها لتقدير الدلاكة الإكلينيكية وفقا لهذا الأسلوب والذي تعتبره بيترسون (Peterson, 2008) من أكثر

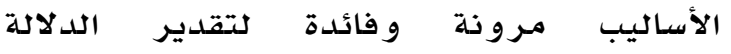
الإكلينيكية مقارنة بالطرق التقليلية الأخرى. و أخيرا تجدر الإشارة إلى أن هذه الطريقة تحتاج لبحث معهق قد يكون خارج إطلار أهداف البـحث الحالي.

\section{نموذج مقترح لفحص الدلالة الإكلينيكية} للمعالجات التجريبية على مستوى المجموعات

ولتحقيق الهدف الأخير من أهداف الدراسـة الحالية فإن النهوذذج الهقتر ح التالي يهدف إلى

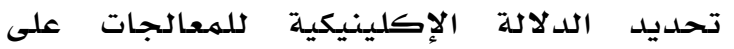
الهـهموعات التجريبة والضابطة ، ويعتمد هذا النهموذج على استخدام الدلالة الإحصائية ولكن بعد تصنيف أفراد الهـهوعتين التجريبية و الضابطة وفقا للهعايير الهستخدمـة في طريقة (Jacobson and Truax- جاكبسون- ترو اكس لتقدير الدلالة الإكلينيكية، ومن ثم (JT), 1991)

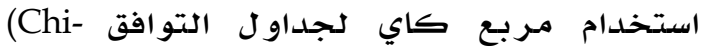
Square for crosstabulation) كان هناك علاقة دالة إحصائيا بين متغيري المسجمو عة (تجر يبيـة - ضابطة) و تصنيف أفر اد العينـة تبعا للطريقة المذكورة، وتم استخدام البيانات الافتر اضيـة الواردة في الهثال التربوي

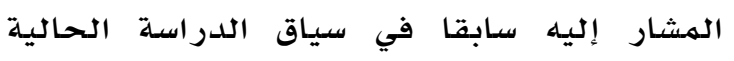

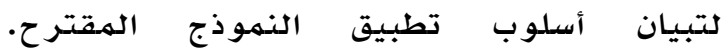
وبالرجوع إلى النتائج الواردة في جدول يلاحظ أن توزيع أعداد أفراد الهـهموعتين التجريبية والضابطة تبعا لتصنيفهم طريقة جاكبسون- ترو اكس(JT) قد كان حسب كما هو موضح في جدول يتضح مـن خلال جدول ع أن إثنان مـن أفراد الهـحموعة التجريبية قد وصلدوا إلى مرحلة العلاج و أن باقي أفراد الهـهموعة (ثلاثة أفراد) قد تحسنوا، أمـا بـانسبـة للهـجموعة الضابطة فإنه لهم يصل إي فرد فيها لهرحلة العلاج وهذه
تطويرهما من قبل كرونباخ Cronbach \& عام 1909. و والمؤشران المقتر حان Gleser, 1959) هما مؤشر ثبات التغير للفرد (RCindiv)، و فيه من الضروري تصنيف الفرد بنسبة دقة لا تقل عن 90\%. ووفي نفس السياق اشار كل من من

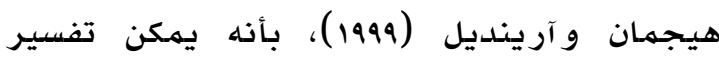

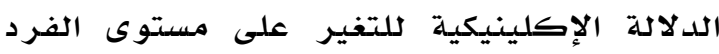
من خلال تعديل طريقة حساب نقطة (CSindiv) القطع و المستتخدمة في طريقة جاطبسون و ترواكس (Jacobson and Truax- (JT), 1991) و ذلك عن طريق الأخذ بعين الإعتبار الدرجة الدار الحقيقية ووعامل ثبات التفير لكل فرد وبحيث يتم استخدام الدلالة الإكلينيكية للفرد لتصنيفه في واحدة من الهـجموعات التالية: الهتدهورين أو المتر اجعيين (Deteriorated) أو مسجموعة من من

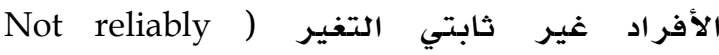
(changed Improved but not ) ولكنهم لهم يتعادجوا لهو (recovered

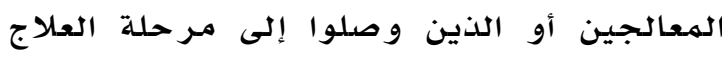
(Recovered)

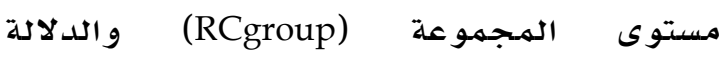

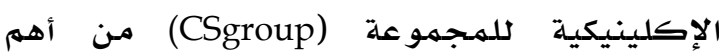
المفاهيم التي قدمها كل من هيجمهان و آرينديل (Hageman and Arrindell, 1999) الدلالة الإكلينيكية و قد اقتر حا أساليب إحصدئية

$$
\text { لحساب كل مؤشر }
$$

الطريقة الخطية الهرمية Hierarchical):

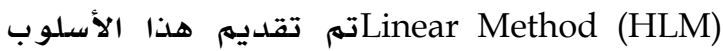

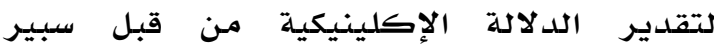
و جر ينبوم (Speer and Greenbaum, 1995) في عام 199 (Bauer, Lambert, \& Nielsen, 2004) و يعتمدد هذا الأسلوب بصورة أساسيـة على نماذج منسحنى النهو (Growth curve models) و وليس على الفرق بين القياس القبلي و القياس البعدي كما هو الحال في الطرق التي سبق ذكرها. وون الضدروري في هذا الأسلوب الحصول على ثلاث قياسـات على الأقل للفرد في مراحل مـتلفة، و بعد ذلك يتم استخدام معادلات خاصدة لتحديل درجلة التغير على مستوى الفرد وفي 
اختبار مـربع كاي لجدوال التوافق لتحقيق الهدف السابق. وقد دلت نتائج هذا التحليل على لهولى أن قيمة مربع كاي قد بلغت 1 م وهي دالة

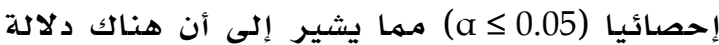

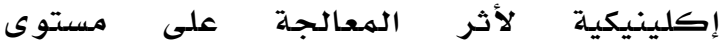

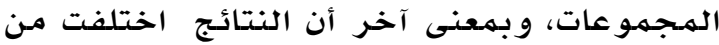

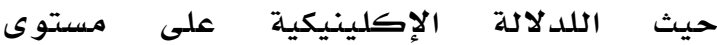

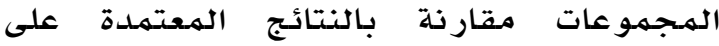
البيانات الافتر اضية في جدول ع وذلك لهات أن أثر

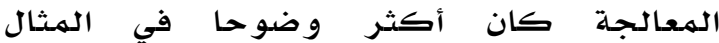
الإفتتر اضي الثاني.

جدول

توزيع افتراضي لتوزيع أعداد أفراد مجموعتين تجريبية وضابطة

تبعا لطريقة جاكبسون - ترواكس (JT)

\begin{tabular}{|c|c|c|c|c|}
\hline المتدهورين & الثابتين & المتحسنين & المعالجيين & التصنيف \\
\hline المتراجعين & $\begin{array}{c}\text { يتغيروا) } \\
\text { يتخ }\end{array}$ & & & المجموعة \\
\hline صفر & صفر & 1 & $\varepsilon$ & التجريبية \\
\hline 1 & r & 1 & صفر & الضابطة \\
\hline
\end{tabular}

يظهر من خلال النتائج السابقة أنه عند استخدام

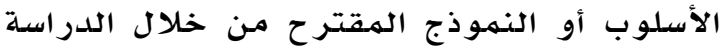

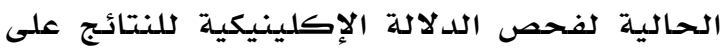
مستوى الهـجموعات، فإنه يمكن القول أنه عندما تكون النتائج دالة إكلينيكيا على مستوى

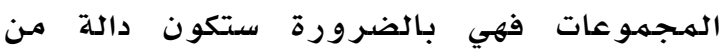
الناحيتين الإحصائية والعملية و لكن العكس غير

صحيح.

التوصيات

إن الهدف الأسـاس من الدراسلة الحالية هو تقديم مفهوم الدلالة الإكلينيكية للباحثين في مجال العلوم النفسية والتربوية وحتى في كافة

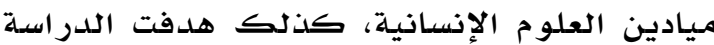
إلى التمييز بين الدلالة الإحصائية و الدلالدة الدية العملية مـن جهة والدلادة الإكلينيكية من جهينة

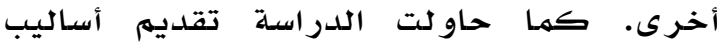
إحصائية محلددة لفحص الدلالة الإكلينيكية

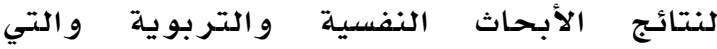
استخدمت المنهج التجريبي لتحقيق أهدافها أو لودئ

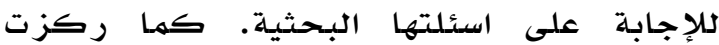

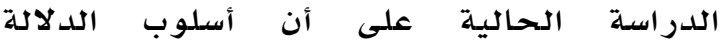

نتيجة متوقعة نتيجة لغياب المعالجة، أما باقي أفر اد المجمهوعة الضابطة فقد توزعوا على باقي المستويات وذذلك على النحو التالي: ثلاثة افراد ضمن فئلة المتحسنين و وفرد واحد ضمن فئة الثابتين و فرد و احد ضهمن فئسة الهتر اجعين. جدول ؛ توزيع أعداد أفراد العينة في الدراسة الإفتراضية وإلمتعلقة بتحسين

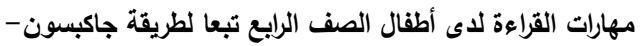
ترواكس (JT)

\begin{tabular}{|c|c|c|c|c|}
\hline المتدهورين & الثابتين & المتحسنين & المعالجيين & التصنيف \\
\hline أو & ل) & & & المجموعة \\
\hline المتراجعين & يتغيروا) & & & \\
\hline صفر & صفر & r & r & التجريبية \\
\hline 1 & 1 & r & صفر & الضابطة \\
\hline
\end{tabular}

ولفحص الدلالة الإكلينيكية للهعالجة على تهماته مستوى المجموعات فقد تم إستخدام إختبار Chi- Square for ) مربع كاي لجدوال التوافق (crosstabulation علاقة دالة إحصائيا بين متغيري الهمجهوعة و التصنيف. وقد اشـارت نتائج هذا التحليل إلى أن

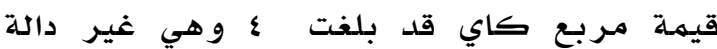

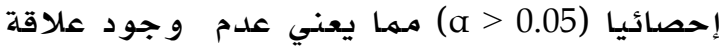
دالة بين متغيري المجموعة و التصنيف. وهذا

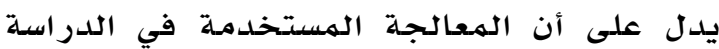
الافتر اضية لهم تكن ذات تاثير كافي بحيث تصل

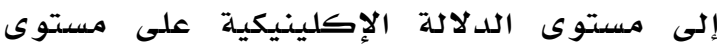
المهجمهوعات، على الرغم مـن ان نفس البيانات كانت كافية للحصول على دلالة إحصائية ودلالة عملية للفروق بين المجموعتين التجر يبيـة و الضابطة.

لكن مـاذا لو تم افتراض أن توزيع افر اد المجمهوعتين كان مختلفا وبحيث كان أثر المعالجة أكثر وضوحا وذلك تبعا للأعداد الواردة في جلدول ه، فهل ستختلف في هذه الحالة نتائج مربع كائ جون

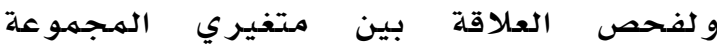
والتصنيف تبعا لتوزيع افر اد المجموعتين

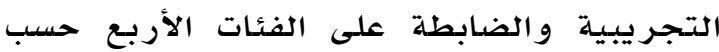
البيانات التي تظهر في جدول ه و فقا لطريقة

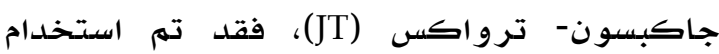




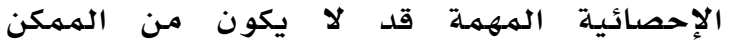
توظيفها بصورة عملية وموسعة في الأبحاث النفسية و التربوية من قبل الباحثين في تلك ولك الميادين نتيجة لصعوبة المعادلات الإحصائية الواجب إستخدامها في تلك الاساليب للخروج بـلالات و معاني بحثية محددة، مـ هنا فإنها مـن

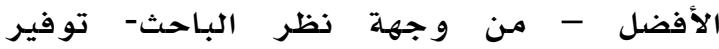

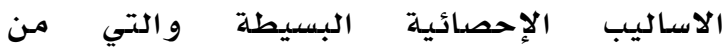

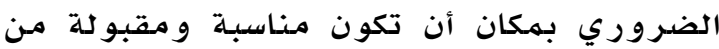

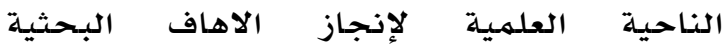
المقصودة. و من خلال ما تم ذكره ذهان تركيز

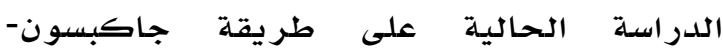

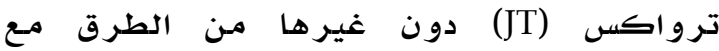
الإثـارة إلا أهميـة الطرق الأخرى خاصدة أنه تم الهم

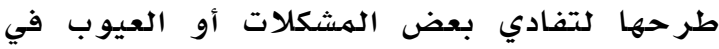

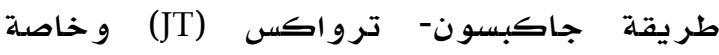
مشكلة إنحدار القيم نحو الوسط. كمها أن أحد أهم أهداف الدراسـة الحالية كان تقديم نموذج

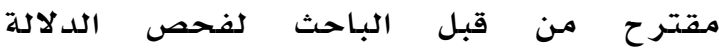

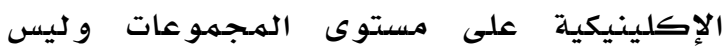
فقط على مستوى الأفراد كما هو الحال في جميع الطرق التي تم إستعر اضها في سياق الدراسلة الحالية، و لتحقيق هذا الهدف تم توظيف طريقة جاكبسون- ترواكس (JT) لتحديد أو لتصنيف أفراد عينة الدراسة في المـجمو عات

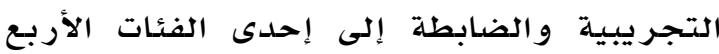
و التي ارتبطت بتلك الطريقة وهذه الفئات هي:

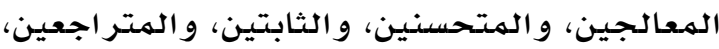
و في خطوة لاحقة تم إقتراح إستخدام إختبار

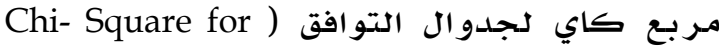

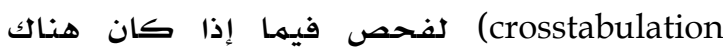
علاقة دالة إحصائيا بين متغيري الهمجموعة والتصنيف، ودلت النتائج التي تم الحصول عليها

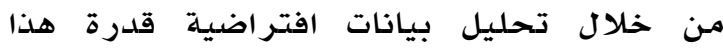
النهوذج المقترح على فحص الدلالة الإكلينيكية

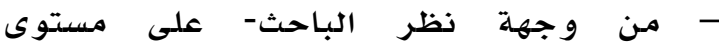

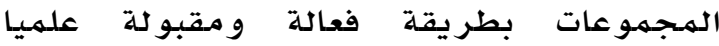
و ومليا.

و أخيرا فإن إن مشكلة الأساليب الإحصديائية

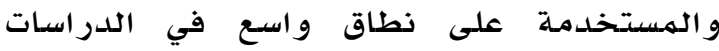

الإكلينيكية هو خاص برصد فيما إذا كان التغير الذي يحصل للفرد بعد التجربة بلة كافيا

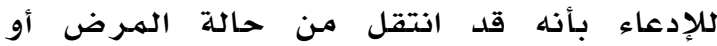
المعاناة من مشكلة سلوكية أو نفسية أو تربوية إلى الشفاء أو التحسن، وربهما في بعض الأحيان قد لا يكون هذا التغير كافيا لإطلاق تلك لوات الإدعاءات بل ربهما قد يكون هذا التغير غير ثابت وهو مايطلق عليه من قبل بعض الأسـاليب التي تم إستعر اضها في سياق الدراسة الحالية "بحالة مناتيلة

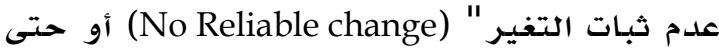
في أسوء الحالات قد تتدهور او تتراجـع حالة

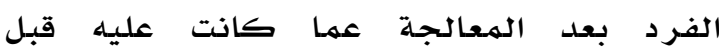

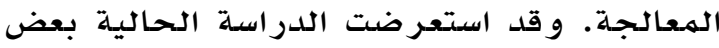
الأسـاليب الإحصائية لفحص الدهالاهلة الإكلينيكية مـع أن الباحث قد قرر التركيز على طريقة جاكبسون- ترواكس البست (JT), 1991)، و ذلك لأن هذه الطريقة هي الأكثر

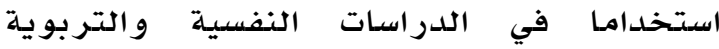

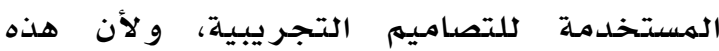
الطريقة- على الرغم مـن بساطتها- فهي حسب ما

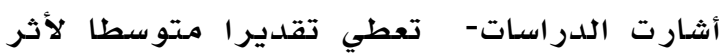

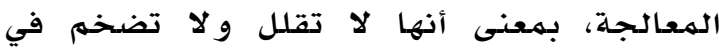

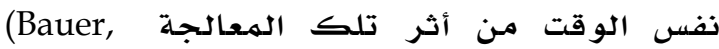

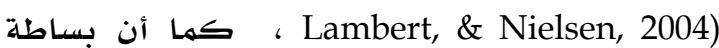
الأساليب الإحصائية التي يمكن استخدامها في

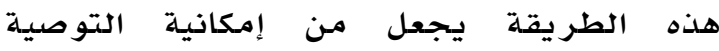
باستخدامها من قبل الباحثين أمـرا متاحا سواء

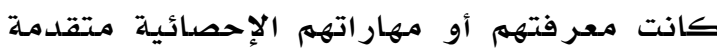

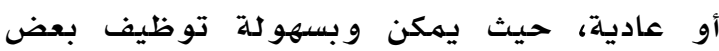

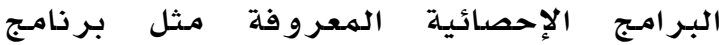

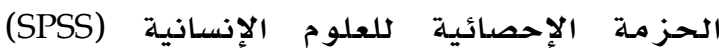

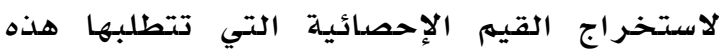
الطريقة لتحديد الدلالة الإكلينيكية للنتائج. ومـن الجدير ذكره أنه يمكن للباحثين الههتمين

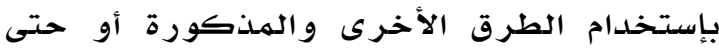
غير المذكورة في سياق الدراسلة الحالية

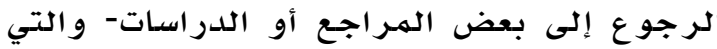

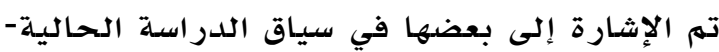
و التي تهكنهم مـن تحقيق أهداف أبحاثهم. و في نفس السياق فإنه يمكن القول بأن بعض المفاهيم 
عودة احمد و الخليلي، خليل (1911). الاحصداء

للباحث في التربية والعلوم الانسانية، عمان:

دار الفكر للنشر و التوزيع.

النجار، عبدالله ( .199)). دراسة تقويمية مقارنة

للاساليب الاحصائية التي أستخدمت في

تحليل البيانات رسائل الماجستير في كل

من كلية التربية في جامعة أم القرى بمكة

المكر مـة وكليـة التربية في جامعة الملك

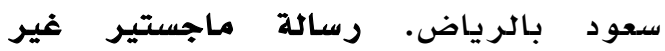

منشورة، كلية التربية، جامعة أم القرى.

نصار، يحيى (Y...r). استخدام حجم الاثر لفحص

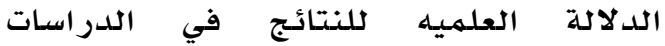

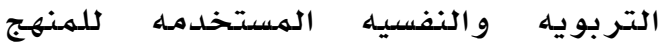

الكمي، مجلة العلوم التربوية والنفسيهـ

البحرين، المجلد السـابع_ العدد الثاني.

Bauer, S., Lambert, M., \& Nielsen, S. (2004).

Clinical Significance Methods: A

Comparison of Statistical Techniques. Journal of Personality Assessment, 82(1), 6070.

Campbell, T. C. (2005). An introduction to clinical significance: An alternative index of intervention effect for group experimental design. Journal of Early Intervention, 27, 210227.

Cronbach, L., \& Gleser, G. (1959). Interpretation of reliability and validity coefficients: remarks on a paper by Lord. Journal of Educational Psychology, 50, 230237.

Gulliksen, H. (1950). Theory of mental tests. New York, NY: Wiley.

Hageman, W. J., \& Arrindell, W. A. (1999). Establishing clinically significant change: increment of precision and the distinction between individual and group level analysis. Behaviour Research and Therapy, 37, 1169-1193.

Hansen, N., Lambert, M. J., \& Forman, E. M. (2002). Comparisons of clinically significant change in clinical trials and naturalistic practice settings: The dose-effect relationship and its implication for practice. Clinical Psychology: Science and Practice, 9, 329-343.
النفسية و التربوية أنها تتعامل مـع المتوسطات

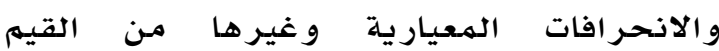

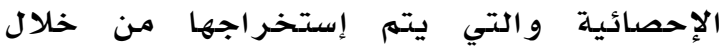
المججموعات وهنا قد يتم - وبصدرة غير مقصودة - إغفال ذلك التغير الذير من المفترض أن يحصل على مستوى الفرد و ليس

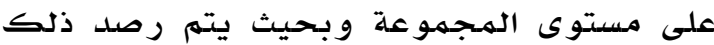
التغير الذي حصل للفرد بعد تعرضده للهمعالجة

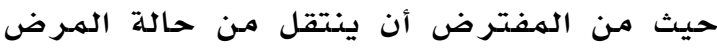

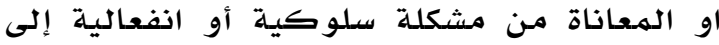

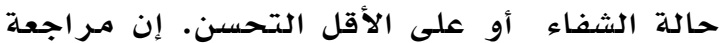

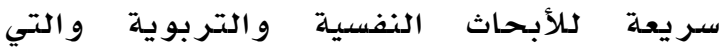

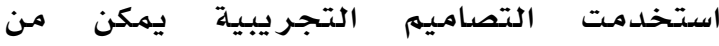
ملاحظة أن معظم هذه الدراسـات إهتمت بالدلالدة الإحصدائية و القليل منها إهتم بالدلالة العملية للنتائج والاقل الاقل أشار إلى ذلك الهـ المفهوم الهام جدا ألا وهو الدلالة الإكلينيكية. و أخيرا فإنه من الههم التوصية بضرورة فحص الدلالدة

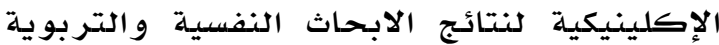

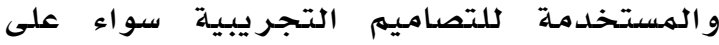
مستوى الأفر اد أو على مستوى المجهمو عات و عددم الإكتفاء بالدلالة الإحصائية أو حتى الدلالة

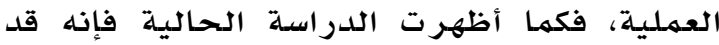
تكون النتائج البحثية التجريبية دالة إحصائيا و عمليا و لكنها ليس بالضرورة أن تكون دالة مـن الناحية الإكلينيكية خاصدة على مستوى الأفراد.

$$
\text { المراجع }
$$

References

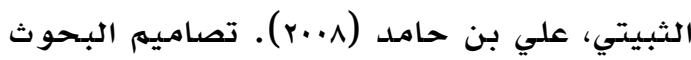

$$
\begin{aligned}
& \text { العلمية ودور ها في صدق نتائج الدر اسـات } \\
& \text { التربوية. مـجلة رسالة الخليج العربي، العدد } \\
& \text { A•1، السنـة هץ، ا-ر|| }
\end{aligned}
$$

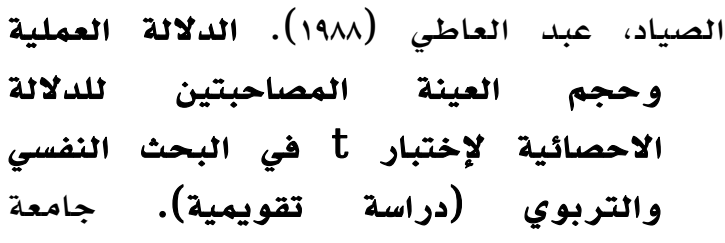

الزقازيق، جههورية مصر العربية. 
Hsu, L. M. (1999). A comparison of three methods of identifying reliable and clinically significant client changes: commentary on Hageman and Arrindell. Behaviour Research and Therapy, 37, 11951202.

Hubbard, R., \& Ryan, P. A. (2000). The historical growth of statistical significance testing in psychology-- and its future prospects. Educational and Psychological Measurement, 60, 661-681.

Huberty, C. J. (1999). On some history regarding statistical testing. In B. Thompson (Ed.), Advances in social science methodology (Vol. 5, pp. 1-23). Stamford, CT: JAI Press. Huberty, C. J. (2002). A history of effect size indices. Educational and Psychological Measurement, 62, 227-240.

Jacobson, N. S., Follette,W. C., \& Revenstorf, D. (1984). Toward a standard definition of clinically significant change. Behavior Therapy, 17, 308-311.

Jacobson, N. S., \& Truax, P. (1991). Clinical significance: A statistical approach to defining meaningful change in psychotherapy research. Journal of Consulting and Clinical Psychology, 59, 12-19.

Kendall, P. C. (1999). Clinical significance. Journal of Consulting and Clinical Psychology, $67,283-284$.

Kendall, P. C., Marrs-Garcia, A., Nath, S. R., \& Sheldrick, R. C. (1999). Normative comparisons for the evaluation of clinical significance. Journal of Consulting and Clinical Psychology, 67, 285-299.

Lambert, M. J., Whipple, J. L., Smart, D.W., Vermeersch, D. A., Nielsen, S.L., \& Hawkins, E. J. (2001). The effects of providing therapists with feedback on patient progress during psychotherapy: Are outcomes enhanced? Psychotherapy Research, 11, 49-68.

Lord, F., \& Novick, M. (1968). Statistical theories of mental scores. Reading, MA: Addison-Wesley.

McGlinchey, J. B., \& Jacobson, N. S. (1999). Clinically significant but impractical?: A response to Hageman and Arrindell. Behavior Research and Therapy, 37, 1211-1217.

Peterson, L. (2008). "Clinical" Significance: "Clinical" Significance and "Practical"
Significance are NOT the Same Things. Paper presented at the annual meeting of the Southwest Educational Research Association, New Orleans, February 7.

Speer, D. C. (1992). Clinically significant change: Jacobson and Truax (1991) revisited. Journal of Consulting and Clinical Psychology, 60, 402-408.

Stevens, J.P. (1996). Applied multivariate statistics for the social sciences (3rd ed.). NJ: Lawrence Erlabaum.

Thompson, B. (1998). Encouraging effect size reporting is not working: The etiology of research resistance to changing practices. Paper presented at the annual meeting of the Southwest Educational Research Association (Houston, Tx, January, 1998). (Eric Document Reproduction Service No. ED 416214).

Thompson, B. (2006). Foundations of behavioral statistics: An insight-based approach. New York: The Guilford Press.

Thompson, B. (2002). "Statistical", "practical," and "clinical": How many kinds of significance do counselors need to consider? Journal of Counseling and Development, 80, 64-80.

Wilkinson, L., \& APA Task Force on Statistical Inference. (1999). Statistical methods in psychology journals: Guidelines and explanations. American Psychologist, 54, 594604. 